\title{
Schopenhauer y las Investigaciones filosóficas sobre la esencia de la libertad humana de Schelling
}

\author{
Fernando Martínez Herrera ${ }^{1}$
}

Recibido: 08 de junio de 2017 / Aceptado: 12 de marzo de 2018

Resumen. Aunque con cierta frecuencia se ha hablado de la influencia del «Tratado sobre la libertad» de Schelling sobre la metafísica de Schopenhauer, la tradición apenas ha prestado atención a los numerosos pero muy dispersos materiales, publicados e inéditos, que conciernen a la relación y la polémica de Schopenhauer con dicho tratado. El artículo ofrece una exposición ordenada de tales materiales, mostrando cuáles fueron las objeciones fundamentales de Schopenhauer al escrito y tratando de determinar la motivación última de la polémica. Asimismo, se comentan las declaraciones del propio Schopenhauer con respecto a la supuesta influencia, ofreciendo claves para una interpretación de las mismas distinta a la usual.

Palabras clave: ética; filosofía postkantiana; ontología, Schelling, Schopenhauer.

\section{[en] Schopenhauer and Schelling's Philosophical Inquiries into the Essence of Human Freedom}

\begin{abstract}
Even though it is not unusual to read about the influence of Schelling's "Freedom Essay" on Schopenhauer's metaphysics, tradition has almost completely overlooked the considerable amount of scattered passages that can be found in Schopenhauer's works and unpublished writings that deal with his relation and discussion of Schelling's 1809 essay. This article examines the whole of these documents, highlighting Schopenhauer's main objections to Schelling's text and trying to establish the polemics' ultimate motivation. Furthermore, it deals with Schopenhauer's own statements about the so-called influence, giving some possible keys for an interpretation of such statements different from the most common one.
\end{abstract}

Key words:ethics; ontology; post-kantian philosophy; Schelling; Schopenhauer.

Sumario: 1. Introducción; 2. La recepción del «tratado sobre la libertad» en el joven Schopenhauer (1812-1816); 3. El «tratado sobre la libertad» en el Schopenhauer maduro (1818-1860); 4. Para la interpretación de las principales objeciones de Schopenhauer al «tratado sobre la libertad»; 5. Influencias y plagios; 6. Conclusiones.

Cómo citar: Martínez Herrera, F. (2019): "Schopenhauer y las Investigaciones filosóficas sobre la esencia de la libertad humana de Schelling", en Revista Anales del Seminario de Historia de la Filosofía 36 (1), 147-174.

$1 \quad$ Universitat de Barcelona

fermherrera@yahoo.es

ORCID: 0000-0001-9683-498X 


\section{Introducción}

El tratado Investigaciones filosóficas sobre la esencia de la libertad humana y los objetos con ella relacionados, también conocido como Freiheitsschrift o «Tratado sobre la libertad», y del que se puede decir hoy que es la «obra más conocida» de Schelling ${ }^{2}$, originalmente se publicó dentro de una compilación de Escritos filosóficos del autor en 1809, lo que contribuyó en no escasa medida a que pasara ampliamente desapercibido en su momento ${ }^{3}$. Schopenhauer, sin embargo, estudió dicha recopilación ya en su época de estudiante en Berlín, en 1812, fecha a partir de la cual se inició una relación con el tratado en cuestión que duraría hasta las últimas publicaciones del filósofo ${ }^{4}$. Con cierta frecuencia se ha querido ver en esta obra de Schelling, donde se lee aquello de «Wollen ist Urseyn», una decisiva influencia sobre la filosofía de Schopenhauer a pesar de las protestas de éste ${ }^{5}$, tanto entre intérpretes de Schelling como entre los propios estudiosos de Schopenhauer ${ }^{6}$. La tarea que aquí nos proponemos es ofrecer una exposición de la recepción y, ante todo, la crítica de Schopenhauer al tratado de Schelling; no obstante, en la medida en que es el propio Schopenhauer quien habla de su relación positiva con el tratado, deberemos entrar hasta cierto punto en la discusión sobre si existe tal influencia y en qué medida. Precisamente, para decidir tal cuestión un requisito previo debería ser el de determinar, antes incluso que las semejanzas en las que se apoya la citada tesis de la influencia, las diferencias, esto es, aquello que separa a Schopenhauer de ese texto de Schelling que presuntamente le habría influido de forma tan decisiva.

2 Cf. Félix Duque, Historia de la filosofia moderna. La era de la crítica, Madrid: Akal 1998, p. 297. Posiblemente la celebridad del Freiheitsschrift se deba ante todo a la atención que le prestó Heidegger en Schellings Abhandlung über das Wesen der menschlichen Freiheit (1971, obra basada en lecciones de 1936). Sin embargo, como indica F. Duque (loc. cit., nota 608), el tratado tuvo en su momento una repercusión casi nula; incluso parece que el propio Schelling no hubiera querido otra cosa, lo que se denota ya en la extraña elección de publicarlo por primera vez dentro de una compilación retrospectiva de «escritos filosóficos».

3 El tratado se publicó en: Philosophische Schriften 1. Band. Landshut: Ph. Krüll, 1809. La decisión de Schelling de publicar el texto dentro de un primer volumen de obras completas (que, por lo demás, no tuvo continuidad) ha dado mucho que hablar. Véase el «Estudio introductorio» de A. Leyte y V. Rühle en: F.W.J. Schelling, Investigaciones filosóficas sobre la esencia de la libertad humana y los objetos con ella relacionados, tr. $\mathrm{H}$. Cortés y A. Leyte. Barcelona: Anthropos, 1989, p. 7s, especialmente la nota 1, donde (p. 8) leemos: «escondido [el tratado de 1809] en el seno de un volumen de escritos ya conocidos (...), revela la inseguridad y cierto miedo a un ambiente filosófico dominado por completo por Hegel». El motivo aducido es harto dudoso, pues en 1809 Hegel aún estaba muy lejos de dominar el ambiente filosófico; F. Duque, op. cit., p. 297s, n. 608, desmonta el argumento del «dominio hegeliano» de Leyte y Rühle con contundentes razones, y ofrece una versión mucho más verosímil de los motivos del, por así decir, autoenclaustramiento de Schelling en torno a 1809.

4 Remitiendo a la paginación de la edición de Arthur Hübscher de las obras de Schopenhauer: Sämtliche Werke, VII vols., Leipzig: Brockhaus, 1988 (4 edic.), en el artículo empleamos las siglas W I y W II para los dos tomos de Die Welt...; KKP, para el apéndice de W I («Kritik der Kantischen Philosophie»); WN, para Über den Willen in der Natur; BGE, para Die beiden Grundprobleme der Ethik; SzG, para la edición de 1847 de Über die vierfache Wurzel des Satzes vom zureichenden Grunde; y P I y P II para Parerga und Paralipomena. La abreviatura

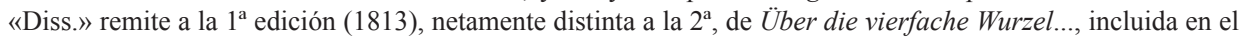
vol. VII de la edición de Hübscher de las Werke. La sigla HN, seguida por números romanos, remite a los cinco volúmenes (el IV, con dos partes) de Der handschriftliche Nachlass, ed. de A. Hübscher, Múnic: DTV, 1985. Para las Philosophische Vorlesungen aus dem hanschriftlichen Nachlass, según la edición de V. Spierling (4 vols., Múnic-Zúric: Piper, 1984-1986) empleamos las siglas: TgV (Bd. 1: Theorie des gesammten Vorstellens, Denkens und Erkennens); MdN (Bd. 2: Metaphysik der Natur); y MdS (Bd. 4: Metaphysik der Sitten). La sigla $\mathrm{GBr}$, en fin, remite a la edición de Hübscher de las Gesammelte Briefe, Bonn: Bouvier, 1987. Las traducciones de las citas de Schopenhauer son nuestras salvo cuando indicamos lo contrario.

$5 \quad C f$. P I, 142, citado y comentado infra.

$6 \quad C f$., infra, el $\S 4$. 
No es baladí señalar que tal requisito rara vez se ha cumplido, si es que alguna, en la tradición ${ }^{7}$. Y para satisfacerlo, seguramente no hay guía mejor que recurrir a las propias objeciones de Schopenhauer contra el tratado: pero en primer lugar hay que conocerlas. Y es así que Schopenhauer no dejó las cosas fáciles a los intérpretes en este punto: en sus obras publicadas, tan sólo unos pocos pasajes tocan, y sólo parcialmente, el tema, lo que hace necesario recurrir a los manuscritos inéditos y otros documentos del Nachlass. Como veremos, aun después de reunir y combinar todos los materiales, su polémica con el tratado de Schelling dista de ser una crítica sistemática y en profundidad; incluso apenas ofrece pautas para una exposición ordenada. Los pasajes críticos consisten en general en rápidas pinceladas que a menudo se reducen a breves parodias o alusiones irónicas; tan sólo en unas pocas ocasiones se desarrollan auténticos argumentos. Con tales elementos, pues, no es mucho lo que puede construirse. Dada la casi total ausencia de argumentaciones que expliquen la polémica y la dispersión de los pasajes en que ésta se plantea, podría ser tentador tratar de cubrir las lagunas a base de conjeturas más o menos disimuladas, pero, frente a tal modo de proceder, del que gustan ciertos intérpretes ${ }^{8}$, nosotros nos atendremos a los elementos que Schopenhauer ofrece, por pocos que sean, tratando a cambio de establecer un marco y una orientación para la interpretación de su crítica. Nos serviremos, pues, del intento de determinar ese Leitmotiv de las objeciones al Freiheitsschrift como un cierto hilo conductor para la exposición de las mismas.

Comenzaremos por una presentación evolutiva de los materiales disponibles acerca de la relación de Schopenhauer con el Freiheitschrift, dividida en dos partes: una primera fase, previa a la publicación de Die Welt als Wille und Vorstellung (1818) y que se desarrolla en los manuscritos juveniles, correspondería a la recepción inicial y primeras críticas del texto de Schelling (§ 2); la segunda, que abarca de 1818 a 1860, consistiría ante todo en la manera como Schopenhauer presentó sus objeciones en sus publicaciones ( $§ 3)$. Como se verá, esta división no obedece solamente a criterios cronológicos sino también de contenido. De este recorrido habremos de obtener, primero, una visión de la evolución de la relación de Schopenhauer con el tratado; segundo, una panorámica de la naturaleza de esos materiales y los problemas que ofrecen para su tratamiento; $y$, tercero, una idea del juicio general de Schopenhauer acerca del texto de Schelling. Tratar de determinar dicho juicio, decíamos, será nuestro hilo conductor en los primeros apartados. En el $\S 4$ expondremos y defenderemos nuestra interpretación general de esta polémica particular de Schopenhauer con Schelling y finalmente abordaremos la cuestión de la supuesta influencia del texto de Schelling en la metafísica de Schopenhauer (§ 5), en la medida en que este mismo saca el tema a colación.

\footnotetext{
En general podemos decir que tradicionalmente se ha estudiado muy poco la relación de Schopenhauer con los postkantianos en general y con Schelling en particular. Nosotros hemos intentado poner remedio a esa situación en nuestra tesis doctoral: F. Martínez Herrera, La recepción y la crítica de la filosofía postkantiana en Schopenhauer, 2 vols., leída el 28 de enero de 2016 en la Universidad de Barcelona, accesible online (sept. 2016) en el sitio: http:/www.tdx.cat/handle/10803/394022. El capítulo 3 se consagra al estudio de la relación con Schelling en general, incluyendo un apartado relativo al Freiheitschrift del que el presente artículo es una reconfección abreviada.

8 Ejemplos abundantes del recurso a tal expediente los encontramos, más que en relación con Schelling, en el tratamiento, en bastantes autores, de la polémica de Schopenhauer con Hegel, que presenta problemas similares a los arriba expuestos y cuya dificultad de reconstrucción es incluso mayor.
} 


\section{La recepción del «tratado sobre la libertad» en el joven Schopenhauer (1812- 1816)}

Los primeros comentarios de Schopenhauer sobre el Freiheitsschrift se encuentran en el cuaderno que los editores del Nachlass titularon «Schelling II», que consiste en «Notas al primer tomo de los Escritos Filosóficos de Schelling», escritas a comienzos de 1812, cuando Schopenhauer estudiaba en Berlín. De la lectura de esas notas no se desprende que se entusiasmara en lo más mínimo por la obra, ya que casi todas ellas son objeciones críticas, algunas de cierta dureza; sin embargo, tampoco se desprende un especial rechazo: no hay en el cuaderno ningún intento de pronunciar un juicio general definitivo sobre el libro, ni ninguna disensión fundamental, sino tan sólo una colección de objeciones puntuales dispersas ${ }^{10}$. Entre las notas destaca, por su nombre, un pasaje que lleva el epígrafe «Sobre todo el ensayo sobre la libertad», que, sin embargo, a pesar de su título, no ofrece un auténtico juicio o crítica de conjunto, sino más comentarios puntuales: Schopenhauer pone especial énfasis, en todo caso, en la acusación de imitar en todo el libro el Mysterium Magnum de Jakob Böhme ${ }^{11}$, acusación que publicará posteriormente, como veremos. Por dura que sea esta crítica -que aun los intérpretes de Schelling conceden, por lo demás ${ }^{12}-$, no se expresa aquí ni un desacuerdo fundamental, ni lo contrario, con respecto al conjunto de la obra, como no se hace en ninguna de las demás críticas del cuaderno.

De estas críticas, la más notable se halla en el comentario más extenso del cuaderno, que contiene la objeción según la cual, con la exposición schellingiana del determinismo moral, la vida resultaría una pieza de teatro conocida de antemano, un cálculo algebraico, reproche que nos recuerda al de «fatalismo moral» dirigido a Fichte en la misma época ${ }^{13}$. Curiosamente, la página que despierta las protestas

9 Cf. HN II, 306-315: «[Schelling II] Anmerkungen zum ersten Band von Schellings philosophischen Schriften». Hübscher no lo especifica, pero las notas al Freiheitsschrift comienzan con el comentario a la p. 406 del volumen, hasta el final del cuaderno (HN II, 312-315). Todas las referencias al libro de Schelling en este artículo remiten a la paginación de la edición de 1809, la empleada por Schopenhauer, a fin de facilitar la contrastación de las citas con la edición del Nachlass de Schopenhauer (en HN II y HN V); daremos además, cuando las citas lo requieran, la equivalencia de la edición KFA de las obras de Schelling.

10 Así, en las pp. 406s del libro de 1809, Schopenhauer discute el modo como Schelling propone reinterpretar las contradicciones; en pp. 413 y 427s, la posición que, en algunos pasajes, le parece a Schopenhauer un realismo o dualismo dogmático oculto; en pp. 427 y 478, protesta por el desdén que expresa Schelling respectivamente hacia la concepción fichteana de Dios como «orden moral del mundo» y hacia la moral kantiana del deber; y en otros lugares señala las inconsistencias lógicas (en p. 501, en relación con que el mal sea un no-ser, Unwesen) en las que incurre Schelling, cuando no apela a subterfugios ( $c f$. el comentario a la p. 503, sobre la despreocupación de Schelling acerca de los posibles malentendidos, en un pasaje que Schopenhauer compara con otro de la Grundlage de Fichte de 1794, y cf. además las últimas líneas del epígrafe «Über den ganzen Aufsaz über die Freyheit», en HN II, 314, sobre el tono amenazante que dominaría el libro).

$11 C f$. HN II, 314, epígrafe «Über den ganzen Aufsaz über die Freyheit».

12 Por ejemplo, A. Leyte y V. Rühle en op. cit, p. 65: el libro de Schelling sería «casi un plagio directo, por lo menos en la apropiación de determinados contenidos, del pensamiento de Jacob Böhme». Estos autores no mencionan a Schopenhauer en este contexto concreto, pero sí lo hace F. Duque en op. cit., p. 298 (texto y nota 608), donde aplaude el «buen olfato» de Schopenhauer al remitir (en HN V, 148) la doctrina del Urgrund, más allá de Boehme, a los valentinianos. Incluso Xavier Tilliette, en su monumental monográfico sobre Schelling, menciona las acusaciones de Schopenhauer (tomadas de la más antigua edición del Nachlass, la colección de J. Frauenstädt de 1864) sin oponer apenas resistencia: $c f$. X. Tilliette, Schelling. Une philosophie en devenir, París: Vrin, 1970 (reimp. 1992), vol. I, 535 y 538. En la larga nota sobre Schopenhauer y Schelling en II, 432, Tilliette, a la vez que menciona de nuevo las críticas de Schopenhauer sin refutarlas, se desquita al sugerir a cambio que las doctrinas del Schelling de 1809 debieron de influir en el joven Schopenhauer sin que éste lo quisiera admitir.

13 Para el «fatalismo moral» en Fichte, $c f$. los comentarios al System der Sittenlehre en HN V, 53 (Hübscher informa 
de Schopenhauer se encuentra dentro de la exposición de la doctrina kantiana de la libertad inteligible, que elogiará en 1813. La primera parte del comentario habla, un tanto oscuramente -son, tengámoslo presente, notas que Schopenhauer escribe para sí-, del empleo trascendente de las formas del fenómeno; cabe admitir, como quiere Schelling, que «a la base del fenómeno del hombre en el tiempo reside algo fuera de todo tiempo», «fuera de todas las condiciones del fenómeno», pero «si uno quiere ajustar estas condiciones al concepto -por lo demás correcto- de ese algo, entonces obtiene monstra $\rangle^{14}$. No está del todo claro a qué contesta o qué comenta exactamente Schopenhauer aquí15; pero es evidente la orientación kantiana de la objeción: Schelling estaría, en el pasaje, entrando en el ámbito de lo trascendente; de ahí los monstra mencionados. Pero lo que motiva por encima de todo la polémica de Schopenhauer en ese lugar es la doctrina de la necesidad de las acciones humanas, que Schelling ejemplifica con la traición de Judas. El determinismo schellingiano haría «inútiles y superfluas» la vida humana tanto como «toda religión y filosofía»; en contra, Schopenhauer invoca el «renacimiento» místico, las conversiones y «la sentencia correcta de Platón de que todo mal es un error» ${ }^{16}$. Resulta curioso ver aquí al joven Schopenhauer polemizando con Schelling por sostener éste un determinismo de inspiración spinoziana muy próximo al que él mismo defenderá en su madurez, así como, de modo paralelo, abandonará a ese Platón intelectualista del mal como error en favor del Platón de la elección del daimon propio previa a la «caída» de las almas en el mundo sensible. Ahora bien, esa posterior aproximación nunca llegará a ser una igualdad, sino que hay una serie de matices que distinguen el determinismo moral del Schopenhauer maduro frente al de Schelling: exponerlos aquí y ahora no viene al caso, pero podemos sugerir, primero, el hecho de que en Die Welt se defiende, a pesar del universal determinismo (para el mundo fenoménico), la posibilidad de un único acto libre en el fenómeno -el de la negación de la voluntad-; segundo, que el determinismo fenoménico de Schopenhauer no se justifica, de modo trascendente, precisamente por ese acto libre extrafenoménico -que es lo que en cambio Schelling sí haría en el tratado (y que sería una muestra de los monstra de los que habla Schopenhauer en 1812)-; y, tercero, que, en cualquier caso, en Schopenhauer el determinismo nunca tiene en en el punto de mira una cosmodicea y menos aún una teodicea, a diferencia del que el Freiheitsschrift presenta. Ya en estas

de que bajo el título de la obra Schopenhauer escribe: «o sia [sistema] del fatalismo moral») y 57 (comentario a p. 358: «Die ganze Fichtesche Philosophie ist zu nennen ein moralischer Fatalismus»); la expresión, dirigida a la ética de Fichte, aparece más tarde publicada en WN, 141, y BGE, 180s.

$14 C f$. HN II, 313, comentario a p. 468 (= SW VII, 386), primer tercio.

15 Probablemente responde a la frase de Schelling según la cual en el hombre hay un sentimiento de «haber sido lo que es desde toda la eternidad, y no haber llegado a serlo sólo en el tiempo»: $c f$. Schelling, SW VII, 386.

16 HN II, 313, comentario a p. 468: «Daß Judas nicht ändern konnte daß er ein Verräther wurde, zeugt von der Verkehrheit der Säzze woraus dies folgt. Überhaupt wird durch Schellings Theorie der Freyheit das Leben ein Schauspiel dessen Scenen und Ausgang man vorher weiß, dessen Zweck daher keiner begreift: ein Auflösen des schon vorhandenen Resultats eines algebraischen Exempels in Zahlen: ein unnützer ennuy, wie verabredete öffentliche ceremonielle Handlungen an Höfen u.s.w. - So unnüzz und überflussig wie das Leben, wird, wenn der moralische Werth des Menschen vor seiner Geburt bestimmt ist, alle Religion und Philosophie: denn Andern die Bosheit der Bösen unschädlich zu machen, ist der Staat gut. Gegen $\mathrm{p} 470$ wende ich besonders ein was die Mystiker Wiedergeburt nennen und alles Bekehren; so auch Platons richtigen Ausspruch daß alles Böse ein Irren ist. - Übereinstimmend mit Schelling ist jedoch eine andre Stelle Platons (ich glaube in Timäos) wo er jeden sein Leben wählen läßt. Auch sehe man de Republica X p. 330». La cita de Platón remite a la edición bipontina; $c f$. Rep. 617e (elección del daimon que nos regirá en la vida). Para la p. 470 de Phil. Schriften I, $c f$. SW VII, 387. 
notas juveniles contrapone, a la perspectiva de salvación colectiva de la humanidad en la historia, en el futuro, propuesta por Schelling, la salvación individual del «renacimiento», la «conversión», posible en todo tiempo. Esa «historia» de Schelling, prefijada, predeterminada, cuyo final se sabe de antemano, anularía el sentido de la ética -«toda religión y filosofía»-: esto es, pues, lo que más choca inicialmente al joven Schopenhauer del tratado de Schelling, junto a la imitación de Böhme. Como veremos más adelante, Schopenhauer, aunque abandonará este primer argumento (debido, justo, a la adopción de un determinismo de estilo spinoziano), seguirá teniendo en el mismo lugar el blanco principal de sus objeciones contra el Freiheitsschrift.

De que, por lo demás, a pesar de no expresarlo en esas notas a los Philosophische Schriften, Schopenhauer sí que se formó un juicio más bien negativo de la obra, y no sólo por lo que tendría de imitación de Böhme, da testimonio una breve anotación a las lecciones de Schleiermacher, que escuchó en verano de 1812, sobre la «Historia de la filosofía en la época del cristianismo»: al explicar el profesor que Escoto Eriúgena afirmaba un «mítico» «retorno de las cosas a Dios» y su «surgir de Dios», Schopenhauer anotó: «esto, con otras palabras, es el cuento schellingiano del fundamento (Grund-Mährchen)» ${ }^{17}$. Aunque aquí no lo especifica, ha de referirse al Freiheitsschrift, donde aparece el famoso concepto del Urgrund, o Ungrund, si bien Schopenhauer podría aludir también a lo que ese mismo año había denominado el «cuento» de Filosofía y religión, opúsculo de Schelling (1804) donde no hay ningún «Grund» explícito que juegue un papel importante, pero sí una exposición «mítica» que puede haber recordado Schopenhauer por las palabras de Schleiermacher ${ }^{18}$. Una separación nítida de las doctrinas de las dos obras de Schelling la expresará Schopenhauer con determinación sólo en $1814^{19}$; pero que el término GrundMährchen alude al Freiheitsschrift es casi seguro, sobre todo a la vista de otras declaraciones posteriores sobre la obra, que pronto vamos a ver.

Ya entre los comentarios a Phil. Schriften de 1812, algo anteriores a los apuntes de la lección de Schleiermacher, se comienza a esbozar esa percepción del tratado de 1809 como un «cuento», si bien todavía no con este nombre: más bien, la primera imagen paródica que se le ocurre a Schopenhauer para describir el «proceso» histórico que el escrito propone es la imagen de un proceso químico -cosa que, por lo demás, posiblemente habría sido del gusto del Naturphilosoph Schelling, de haber conocido las ironías de nuestro filósofo-. En efecto, son dos las ocasiones en que Schopenhauer, en ese cuaderno, compara con procesos químicos el proceso que Schelling expone, y en concreto el de la relación entre el bien y el mal. Dice primero, pues, acerca de cierto pasaje, que en éste «la creación aparece como una reducción [química] del bien (en cuanto Régulo) a partir de su fusión mineral con el

17 HN II, 227 (apuntes «Geschichte der Philosophie zur Zeit des Christenthums bey Schleiermacher»): Schleiermacher dicta que «obgleich alle Dinge so ewig wie Gott sind, nimmt er [Erigena] doch ein Zurückgehn der Dinge in Gott an, das mythisch ist, wie andrerseits ihr Entspringen aus Gott. Wie sie vor der Schöpfung nur im göttlichen Verstand waren, sind sie nachher nichts als Gott». Schopenhauer comenta: «Dies ist mit andern Worten das Schellingsche Grund-Mährchen».

18 Schopenhauer califica un par de veces de «cuento» la doctrina del opúsculo de 1804 de Schelling: cf. en HN II, 327s, los comentarios a Philosophie und Religion, Tübingen: Cotta, 1804, pp. 40, 66 y p. 68. Previamente había denominado así también a la doctrina de la ciencia de Fichte: $c f$. HN II, 60s (comentario a la lección de Fichte «Über die Thatsachen des Bewußtseyns», octubre-diciembre de 1811): «Ich versuche zu erklären wie sich dies ganze Mährchen in F[ichte]s Gehirn entsponnen hat...»

19 Cf. infra lo relativo al fragmento $\mathrm{n}^{\circ} 126 \mathrm{de} \mathrm{HN}$ I. 
mal» ${ }^{20}$ y así «el mundo aparece como unos grandes altos hornos» ${ }^{21}$; después, retoma la comparación química en la nota titulada «Sobre todo el tratado sobre la libertad», donde, después del asunto de la imitación de Böhme, leemos:

Es sumamente divertido, pero innegable, cómo a través de toda esta pulcra teoría mira el químico. Todo -Dios, el mundo, el hombre- es una sal neutra. El álcali se llama: el fundamento, el anhelo, el centro, etc. El ácido se llama: la luz, el entendimiento, el amor. Sólo cuando se neutralizan existe Dios, mundo, hombre, y todo es bueno. El mal radical no es nada más que una descomposición: el álcali se vuelve cáustico. Pero cómo obra el ácido por sí solo, no se declara ${ }^{22}$.

Muchos años después, en las notas de los años 1830 al escrito, aún dirá irónicamente Schopenhauer, movido por la comparación de la relación del mal y el bien con una tormenta, que, según Schelling, «el mundo es, en efecto, una máquina electrificada $»^{23}$.

Que estas metáforas paródicas son para Schopenhauer algo más que una broma se adivina en otros comentarios del cuaderno de 1812 donde sugiere que hay en esta obra de Schelling una fuerte tendencia realista-sustancialista, a la manera dogmática; en particular, cuando señala, en cierto pasaje, que, en la relación afirmada por Schelling de las cosas con Dios como consecuencias del fundamento o accidentes de la sustancia, estos conceptos «se toman, en vez de figuradamente, de forma crasamente materialista ${ }^{24}$; lo cual, por lo demás, se corresponde perfectamente con la acusación de emplear de forma trascendente leyes intelectuales de exclusivo uso inmanente, con lo que, como se nos decía arriba, se obtienen monstra ${ }^{25}$; o, como escribirá Schopenhauer muchos años después, a la base de esta clase de demostraciones y construcciones del despliegue del absoluto «propiamente residen leyes naturales que

20 Regulus, o «régulo», es como se llamaba en la química antigua (y en la alquimia) a la parte más pura de un mineral; hemos traducido Vererzung ( $c f$. la nota siguiente) por «fusión mineral» para la mayor inteligibilidad, aunque propiamente sería más correcto traducir la palabra por «mineralización».

${ }_{21}$ HN II, 314s: «p 494, 95, 96 [Schelling, SW VII, 401ss] erscheint die Schöpfung als eine Reduktion des Guten (als Regulus) aus seiner Vererzung mit dem Bösen; was ganz und gar durchgeführt ist; so daß demnach die Welt

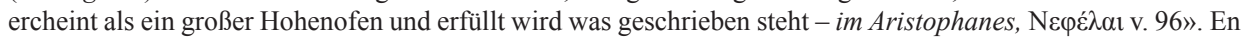
el verso de Las nubes se habla de hombres que prueban, muy convincentes, que el cielo es una tapadera.

22 HN II, 314 («Über den ganzen Aufsaz über die Freyheit»): «Es ist höchst spaßhaft, aber unleugbar, wie in dieser ganzen saubern Theorie der Chemiker durchblickt. Alles, Gott, die Welt, der Mensch, ist ein Neutral-Salz. Das Alkali heißt: der Grund, die Sehnsucht, das Centrum u.s.w. Die Säure heißt: das Licht, der Verstand, die Liebe. Erst indem sie sich neutralisiren ist Gott, Welt, Mensch da, und Alles gut. Das radikale Böse ist nichts als eine Zersezzung: das Alkali wird äzzend. Aber wie die Säure für sich allein wirkt, wird nicht gemeldet».

$23 \mathrm{HN}$ V, 147, coment. a p. 460 del Freiheitsschrift. Allí (= SW VII, 379) dice Schelling que «wie das Gewitter mittelbar durch die Sonne, unmittelbar aber durch eine gegenwirkende Kraft der Erde erregt wird; so der Geist des Bösen (dessen meteorische Natur wir schon früher erklärt haben), durch die Annäherung des Guten, nicht vermöge einer Mittheilung, sondern vielmehr durch Vertheilung der Kräfte»; a lo cual comenta Schopenhauer: «die Welt ist nämlich eine Elektrisirmaschine».

24 HN II, 313: «p 413 [= SW VII, 346] werden die Begriffe: „die Dinge sind Folge von Gott als dem Grunde; oder: sind Accidenzen von Gott als der Substanz" statt bildlich, kraß materialistisch genommen». Véase también, en loc. cit., el comentario a p. 427s (SW VII, 356): Schelling dice que «el idealismo es el alma de la filosofía; el realismo, su cuerpo; sólo ambos juntos constituyen un todo vivo»: Schopenhauer comenta: «p 427 und 428 schmeckt nach dem eigentlich Dualismus, d.h. der Annahme zweyer Wirklichkeiten, der Geisterwelt und der Körperwelt, die man ins Gleichgewicht zu sezzen hat, wobey zuletzt eine Aristotelische Mittelstraße herauskommt».

$25 C f$. HN II, 313, comentario a p. 468, citado supra. 
se mantienen ocultas, y que sin embargo no permitirían en absoluto tal cosa ${ }^{26}$. Pero, al margen de las parodias químicas y la argumentación crítica de aire kantiano que ocultan, fijémonos en cómo, en las fórmulas paródicas que ofrece Schopenhauer en 1812 , los «elementos» o «reactivos» que intervienen en esos «procesos químicos» en los que se «resume» el contenido del tratado de 1809 son conceptos éticos, a la vez que los «procesos» en que intervienen esos «elementos» lo que vienen a explicar es la naturaleza del mundo desde un punto de vista moral -en particular, con miras a una teodicea, obtenida mediante la perspectiva histórica-.

Podemos decir, pues, que el aspecto más importante de la polémica inicial de Schopenhauer con el tratado sobre la libertad, en 1812, es la diferencia de posiciones en lo que concierne a la posibilidad de salvación moral y el rechazo del recurso, en Schelling, al «cuento» de un proceso histórico que brindaría tal salvación de la humanidad a escala colectiva. Esto resulta todavía más manifiesto en dos importantes fragmentos de 1814. En el primero de ellos, Schopenhauer establece una división de las «etapas» de Schelling según criterios soteriológicos: de las tres posiciones dogmáticas en las que habría recaído Schelling, la tercera, correspondiente al tratado de 1809, se resume para Schopenhauer en la proposición: «nosotros, espíritus que no tenemos reposo alguno, aún no lo hemos tenido nunca, hemos devenido, llegaremos a alcanzarlo»: frente a la primera posición, la de la Naturphilosophie y Spinoza, y la segunda, la de Filosofía y religión y «todos los sistemas emanantistas», la de 1809 es la posición de «todas las teorías creacionistas, el teísmo racional, Schelling [en el tratado] sobre la libertad humana $\rangle^{27}$. En el otro fragmento de 1814, algo posterior, de nuevo Schopenhauer compara «etapas» (la de 1804 y la de 1809): dice aquí que «la unificación de cielo e infierno en nosotros» es una «unificación que, por medio del uso trascendente del tiempo y del principio de razón en general, se ha intentado explicar falsamente, ora mediante la caída, emanación, ora (como Schelling [en] "sobre la esencia de la libertad") mediante [un] devenir absoluto, eterno» ${ }^{28}$. En estos dos fragmentos se alude, por supuesto, a la pugna entre bien y mal de la que habla

$26 \quad C f$. HN IV-2, 10 (Senilia, no 29, 1853). Cf. nuestra nota 77.

27 HN I, 78s, no 126 (Weimar, principios de 1814): «Das Hauptproblem der Philosophie bringt jede Dogmatik auf

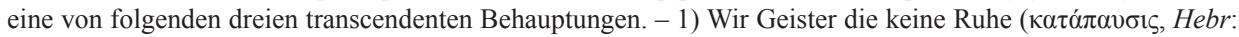
IV) haben, können auch eben nimmermehr Ruhe finden (Spinoza, Schelling in der Weltseele und den Ideen zur Naturphilosophie) - 2) Wir Geister die keine Ruhe haben, haben sie nur verloren, können sie wiederfinden (Alle Emanationssysteme; Schelling in Philosophie und Religion) - 3) Wir Geister die keine Ruhe haben, haben sie noch nie gehabt, sind geworden, werden zu ihr gelangen. (Alle Schöpfungstheorien, rationaler Theismus, Schelling über die menschliche Freiheit.) - »

28 HN I, 168, n 274 (1814): «Diese Identität [des Subjekt des Wollens mit dem des Erkennens] ist eben die Vereinigung von Himmel und Hölle in uns, welche Vereinigung man, durch transcendenten Gebrauch der Zeit und des Satzes vom Grunde überhaupt, bald durch Abfall, Emanation, bald (wie Schelling "über das Wesen der Freiheit”) durch absolutes, ewiges Werden, fälschlich zu erklären gesucht hat». Con la «falsa explicación» mediante «caída» y «emanación» se alude de nuevo a Filosofía y religión. En cuanto a la terminología «Himmel und Hölle in uns», es posible que aluda al pasaje del Freiheitsschrift de SW VII, 363: «Im Menschen ist die ganze Macht des finstern Prinzips und im ebendemselben zugleich die ganze Kraft des Lichts. In ihm ist der tiefste Abgrund und der höchste Himmel, oder beide Centra». Schopenhauer, según se ve, estaría de acuerdo con eso, pero no con la mediación que después lleva a cabo Schelling en el texto. Es curiosa en este fragmento, por lo demás, la posición transitoria por la que Schopenhauer expresa la antigua oposición juvenil entre mundo fenoménico y mundo atemporal, o «conciencia empírica» y «conciencia mejor», como una oposición entre sujeto volente y sujeto cognoscente. Ello se explicaría porque es el segundo el que abre la posibilidad de la liberación o salvación que posteriormente denominará «negación de la voluntad». La misma antítesis está a la base del juego de interpenetración de «mundo como voluntad»y «mundo como representación». Schopenhauer, sin embargo, no seguirá expresándola como oposición de sujeto volente y cognoscente. 
Schelling en la obra, especialmente en el pasaje donde traza una concisa historia de la humanidad desde ese punto de vista, pasaje sobre el cual Schopenhauer nunca escribiría nada de forma explícita ${ }^{29}$; una historia en la que, como en ocasiones anteriores (el Sistema del idealismo trascendental de $1800^{30}$ y el opúsculo de $1804^{31}$ ), Schelling da algunas indicaciones sobre la historia y los tiempos venideros ${ }^{32}$. En un fragmento algo posterior a éstos, de 1816, Schopenhauer opone a la primera o primeras «etapas» de Schelling (una o tres, según se considere la estructura formada por Transcendental-, Natur- e Identitäts-philosophie) los posteriores y diversos «ensayos dogmáticos» de Schelling, «cuyo carácter de cuentos saltaba a la vista»" Con esos «intentos» o «ensayos» (Versuche) que son «cuentos», Schopenhauer ha de referirse a los tratados de 1804 y 1809.

Entre tanto, en la primera obra publicada de Schopenhauer, la disertación Sobre la cuádruple raiz del principio de razón suficiente (1813), si bien se polemiza con el Schelling del sistema de la identidad ${ }^{34}$, la única referencia al tratado de la libertad de 1809 es positiva: concierne a un tema extrañamente ausente en el cuaderno de 1812, a saber, el de la exposición schellingiana de la teoría kantiana de la libertad inteligible, pasaje que Schopenhauer ensalzaría en varias ocasiones, pero que unas décadas más tarde ocasionará, tras la de Böhme, una segunda acusación de plagio. Hay diversos indicios de que Schopenhauer conoció dicha teoría de la mano de Schelling, sin tener inicialmente conciencia del origen kantiano de la misma: en efecto, hacia comienzos de 1813, cuando encuentra en la Nueva crítica de la razón de Fries una exposición similar, Schopenhauer aplaude lo «mucho verdadero sobre la libertad» que hay en el pasaje, añadiendo que en éste «ya residen los rasgos fundamentales de lo que Schelling desarrolló en 1809 en su escrito sobre la libertad»: aquí parece, pues, que Schopenhauer atribuye la doctrina a Schelling, mientras que ve en Fries una anticipación de la misma (la Neue Kritik es de 1807) ${ }^{35}$. Poco después, hacia mayo de 1813, Schopenhauer escribe anotaciones sobre la Crítica de la razón pura y, al toparse con la exposición kantiana, anota, aparentemente sorprendido: «en lo dicho aquí... reside toda la teoría de la libertad de Schelling ${ }^{36}$. No obstante esto, de momento no ve ninguna razón para hablar de plagio, sino que se limita a autocorregirse, sin dejar de admirar la versión de Schelling casi tanto como el pasaje original kantiano.

29 No hay, en las notas al tratado de HN II y HN V, ninguna referencia ni alusión al pasaje (SW VII, 377ss). No sucede lo mismo con los pasajes sobre filosofía de la historia de Phil. u. Rel. y el System de 1800.

30 Cf. Schelling, System des transcendentalen Idealismus, SW III, pp. 587-604. Schopenhauer discute el pasaje en HN II, 338 (comentario a las pp. 417-441 de la edición de 1800).

31 Cf. especialmente, en Philosophie und Religion, el epígrafe «Freiheit, Sittlichkeit und Seligkeit: Endabsicht und Anfang der Geschichte»; Schopenhauer discute con irritación varios pasajes de dicho epígrafe en HN II, 327 (comentarios a las pp. 57 y 64-66 [= Schelling, SW VI, 53 y 57s]).

32 Cf. Schelling, Freiheitsschrift, SW VII, 377ss.

33 HN I, 362, $\mathrm{n}^{\circ} 542$ (1816): «Die eigentliche, von Schelling zuerst angestimmte Naturphilosophie, ist bloß ein Aufsuchen von Ähnlichkeiten und Gegensätzen in der Natur: welche Betrachtung an sich interessant ist und hie und da nützlich werden kann, nie aber eine Philosophie ausmacht. Daher mußte auch Schelling mit mehreren von jener Betrachtung der Natur unabhängigen dogmatischen Versuchen auftreten, denen er kein andres Fundament gab als intellektuelle Anschauung und deren Mährchenhaftes in die Augen fiel».

34 Cf. Diss, $\S 42$, pp. 70 y 71s. Estos dos pasajes desaparecen en la edición de 1847 (SzG).

35 HN II, 364, «Zu Fries» (Hübscher data el cuaderno entre 1812 y comienzos de 1813); comentario a Neue Kritik der Vernunft, Theil 2, pp. 242s: «Sehr viel Wahres über die Freiheit, in dem schon die Grundzüge von dem liegen was Schelling 1809 in seinem Aufsatz über die Freiheit ausgeführt hat».

36 HN II, 280, coment. a Kant, KrV: «577-582. Im hier und oben 566-69 (*conf. 826) Gesagten liegt Schellings ganze Theorie der Freiheit». Las páginas citadas de la $\mathrm{KrV}$ corresponden a la $5^{\mathrm{a}}$ ed., igual a la segunda (B). 
Y así, en efecto, en la disertación doctoral, publicada en noviembre, al tratar el tema del «carácter inteligible», describe el pasaje de Kant como «una incomparable obra maestra de la profundidad humana, digna de la máxima admiración», a lo que añade que, por su lado, «Schelling ha dado, en el primer tomo de sus Escritos, pp. 465-473, una muy estimable exposición aclaratoria de ello», a la cual Schopenhauer remite al lector $^{37}$.

De manera que, antes de la publicación de Die Welt..., disponemos ya de un enjuiciamiento general sobre el libro de Schelling, en dos direcciones opuestas: por una parte, se trata de un «cuento» con el que Schopenhauer tiene serias diferencias desde el punto de vista ético-soteriológico - esta crítica de momento permanece inédita-, pero, por otra, el escrito incluye como mínimo un importante pasaje que Schopenhauer no se ruboriza a la hora de aplaudir ni de remitir a él en su primera obra publicada -donde se distancia en cambio de la «filosofía de la identidad»-. Con ello tenemos la pauta, con cierto predominio de la actitud crítica y negativa, de la característica ambivalencia de Schopenhauer frente a Schelling en general, y al Freiheitsschrift en particular, que se mostrará en sus futuras publicaciones ${ }^{38}$.

\section{El «tratado sobre la libertad» en el Schopenhauer maduro (1818-1860)}

Prescindiendo del elogio puntual de 1813 al modo como Schelling resume la doctrina kantiana de la libertad inteligible, la imagen sarcástica del «cuento»es, según hemos visto, la forma en que queda fijado provisionalmente el juicio sobre el tratado sobre la libertad al llegar el momento de redactar la Hauptwerk: en efecto, en Die Welt als Wille und Vorstellung, aunque Schopenhauer no emplea la palabra «cuento» (Märchen), remite de forma patente a esa misma concepción del tratado de 1809 , junto al de 1804 , en el pasaje del $\S 53$ donde se despacha el asunto del «filosofar histórico» en varias de las «etapas» de Schelling, aludidas de forma tácita. Centrándonos en las alusiones al Freiheitsschrift en particular, tenemos que, primero, Schopenhauer rechaza el auténtico carácter filosófico de una captación histórica del ser (o esencia, Wesen) del mundo, es decir, la que lo concibe desde el punto de vista de un Werden (devenir, llegar a ser), un Gewordenseyn (haber devenido o llegado a ser) o -aquí el sarcasmo es claro- un Werdenwerden (llegar a llegar a ser); los que sostienen tal posición, añade, no sólo establecen un comienzo y un final del mundo (se alude a la primera antinomia kantiana), sino el lugar que ellos mismos ocupan en el «camino» ${ }^{39}$. Si con esto último puede estarse refiriendo a cualquiera de las

37 Diss., § 46, p. 76s: hablando del pasaje de Kant en KrV, B 560-586, comenta que «Schelling hat im ersten Bande seiner Schriften, pp. 465-473 eine sehr schätzbare erläuternde Darstellung davon gegeben. Auf jene Werke mich berufend...». Para el pasaje del Freiheitsschrift, cf. Schelling, SW VII, 383-389.

38 En efecto, tal ambivalencia se manifiesta con frecuencia en el conjunto de materiales en torno a la recepción y crítica de la filosofía de Schelling en Schopenhauer. Por una parte Schelling sería, como Fichte, un «Windbeutel» y un embaucador filosófico del grupo de los «tres sofistas»: pero, entre estos tres, Schelling es el único al que Schopenhauer hace alguna verdadera concesión, aun dirigiéndole ocasionales elogios.

39 W I, § 53, 322: «...wir sind der Meinung, daß jeder noch himmelweit von einer philosophischen Erkenntniß der Welt entfernt ist, der vermeint, das Wesen derselben irgendwie, und sei es noch so fein bemäntelt, historisch fassen zu können; welches aber der Fall ist, sobald in seiner Ansicht des Wesens an sich der Welt irgendein Werden oder Gewordensein oder Werdenwerden sich vorfindet, irgendein Früher oder Später die mindeste Bedeutung hat und folglich, deutlich oder versteckt, ein Anfangs- und ein Endpunkt der Welt nebst dem Wege zwischen beiden gesucht und gefunden wird, und das philosophierende Individuum wohl noch gar seine eigene 
versiones de la filosofía de la historia que Schelling ofreció sumariamente -aparte de la del Freiheitsschrift, Schopenhauer conocía también las de Filosofia y religión y el System de 1800-, el empleo del término Werden ha de aludir al tratado de 1809, único de los mencionados donde dicho término recibe especial énfasis ${ }^{40}$. A continuación, Schopenhauer describe las posibles formas de tal filosofar histórico: ora «una cosmogonía que admite muchas variedades» (la Naturphilosophie, probablemente), ora «un sistema emanantista, doctrina de la caída» -alusión al tratado de 1804-, ora, «finalmente, si por la desesperación por los infructuosos intentos por esas vías es empujado al último camino, [ofrece] a la inversa una doctrina del continuo devenir, manar, nacer, surgir a la luz desde lo oscuro, desde el tenebroso Grund, Urgrund, Ungrund ${ }^{41}$ y cualesquiera otros desatinos ${ }^{42}$. La crítica de estas tres vías del «filosofar histórico» de Schelling halla su principal argumento en el reproche del uso trascendente de la forma del tiempo, junto a otras configuraciones del principio de razón, que se toman como determinaciones de las cosas en sí mismas.

En esta primera crítica publicada al tratado de 1809, pues, Schopenhauer parece poner todo el peso en el punto de vista metafísico, quedando soterrado el debate de tendencia moral que hasta 1818 dominaba de forma clara. De hecho, cabe deducir que todavía lo hace, dada la ubicación del $\S 53$ en Die Welt, a saber, al comienzo del libro IV, consagrado a los temas éticos y la soteriología derivada de la metafísica de la voluntad de Schopenhauer: sin embargo, éste olvida explicitar las razones de la polémica con el «filosofar histórico» que le llevan a ubicarla en ese lugar. De este modo viene a sentarse una pauta para las futuras apariciones de la polémica con el Freiheitsschrift.

En efecto, en las menciones críticas del tratado inmediatamente posteriores a Die Welt, son los aspectos ontoteológicos los que cobran el principal protagonismo: En 1819, Schopenhauer menciona la filosofía que prueba la necesidad de un Urgrund absoluto como una versión encubierta de la prueba cosmológica refutada por Kant ${ }^{43}$;

Stelle auf diesem Wege erkennt».

40 Cf. Schelling, Freiheitsschrift, SW, VII, 358s y 403, por ejemplo.

${ }_{41}$ Aunque Grund se traduce bien por «fundamento», lo dejamos sin traducir junto a los otros dos términos schellingianos, que sí presentan problemas de traducción. En su versión de El mundo... I, P. López de Santa María vierte Urgrund por «fundamento originario» y Ungrund por «desfundamento», poniendo entre corchetes los términos alemanes. «Desfundamento» sugiere, empero, algo así como una «desconstrucción», un «quitar» el fundamento, cosa que no parece ser a lo que Schelling se refiere. H. Cortés y A. Leyte, en su citada traducción del Freiheitsschrift, coinciden con aquélla en cuanto al «fundamento originario», pero vierten Ungrund por «infundamento» (cf. op. cit., pp. 279ss, correspondiente a SW VII, 406ss). F. Duque (op. cit., p. 309) propone, heterodoxo, «fondo originario» para Urgrund y, para Ungrund, «fondo sin fundamento», traducción que se funda en sus reflexiones sobre el término Grund como «fundamento» y «fondo» (op. cit., p. 307, nota 633).

42 Cf. W I, 322: «Solches historisches Philosophieren liefert in den meisten Fällen eine Kosmogonie, die viele Varietäten zuläßt, sonst aber auch ein Emanationssystem, Abfallslehre oder endlich, wenn es aus Verzweiflung über fruchtlose Versuche auf jenen Wegen auf den letzten Weg getrieben, umgekehrt eine Lehre vom steten Werden, Entsprießen, Entstehn, Hervortreten ans Licht aus dem Dunkeln, dem finstern Grund, Urgrund, Ungrund und was dergleichen Gefasels mehr ist, welches man übrigens am kürzesten abfertigt durch die Bemerkung, daß eine ganze Ewigkeit, d.h. eine unendliche Zeit, bis zum jetzigen Augenblick bereits abgelaufen ist, weshalb alles, was da werden kann oder soll, schon geworden sein muß». La última parte de la cita, desde «welches man übrigens...», es una adición de la $2^{\mathrm{a}}$ edición (1844: contra Hübscher, que la data en 1859). Para la traducción de este pasaje de W I, hemos seguido, con modificaciones, la versión de P. López de Santa María.

43 HN III, 10, Reisebuch, $\mathrm{n}^{\circ} 32$ (1819): «Alles Reden vom Absoluten ist durchaus nichts anderes als ein verdecktes Wiederauffrischen des kosmologischen Beweises der von Kant um allen Kredit gebracht und verjagt, nun maskirt und incognito wieder sich einzuschleichen sucht: und hierin besteht fast ganz allein alle Philosophie seit Kant, indem solche bald die Nothwendigkeit eines absoluten Urgrunds demonstrirt bald das Absolute intellektual anschaut bald, schon verzagter, es ahnet u.s.w.» En las últimas líneas, Schopenhauer alude de forma 
un par de años más tarde, caracteriza esta fase del pensamiento de Schelling como aquella en la que se expone «el Dios que se autopare continuamente» ${ }^{44}$; entre tanto, en el texto de las lecciones de Berlín (redactado en su mayor parte hacia comienzos de 1820) ya había aparecido esta misma expresión satírica-el «autoparto» de Dios ${ }^{45}$ como lo peculiar de la «tercera etapa» de Schelling ${ }^{46}$; y en otro lugar de las lecciones se reformulaba la cuestión del «filosofar histórico» mediante la alusión a «largas historias que deben descifrar el enigma del mundo» ${ }^{47}$ : pero esta reformulación se encuentra en la segunda parte de las lecciones, la «Metafísica de la naturaleza», mientras que antes se hallaba al comienzo del libro IV ${ }^{48}$, lo que puede verse como un gesto significativo del giro de la polémica hacia la temática ontoteológica.

Después de este pequeño grupo de pasajes de en torno a 1820, el Freiheitsschrift desaparece de los manuscritos de Schopenhauer hasta 1834: en un fragmento donde esboza su concepción de la filosofía como «desciframiento» del mundo, cuya corrección se confirma en la medida en que es un «cálculo» que «no deja resto» -concepción que aparecerá más tarde en el vol. II de Die Welt y en los Parerga ${ }^{49}$-, tras señalar algunos ejemplos (el materialismo, el teísmo, el panteísmo) que «no cuadran», añade: «En el tratado de la libertad de Schelling he anotado los pasajes donde su cálculo no cuadra» ${ }^{50}$. La frase promete más de lo que cumple, pues si acudimos al ejemplar de Schopenhauer (es decir, el vol. 1 de Phil. Schriften), tan sólo hallamos una anotación personal donde se habla expresamente de un cálculo que no sale bien ${ }^{51}$. En un importante pasaje, Schelling confiesa las posibles flaquezas de la distinción propuesta entre el ser en cuanto Grund y el ser en cuanto existente:

tácita, respectivamente, al Schelling de 1809 -la referencia al Urgrund es inequívoca-, a Fichte o el primer Schelling («intuición intelectual»), y a Fries (mediante la alusión a la Ahnung o Ahndung de lo trascendente).

44 HN III, 87 (Foliant, n ${ }^{\circ}$ 37, 1821): «Die Schelling'schen Lehren als Philosophie schlechthin genommen, also das intellektual angeschaute Absolutum, die Identität des Realen und Idealen, der sich stets selbst gebärende Gott u.s.f. sind Träume ohne Fundament»

45 Schopenhauer alude seguramente a la imagen del «Geburt» («nacimiento» de la Luz a partir de la Oscuridad) en Schelling, SW VII, 360.

$46 \mathrm{TgV}, 253 \mathrm{~s}$. En el pasaje, Schopenhauer establece su concepción de las hasta entonces tres «etapas» de Schelling, siendo la primera la de la identidad y la segunda la de la «caída desde el absolutum» (i.e. Filosofía y religión): «Aber der dritte Schelling schaut an, wie Gott sich selbst gebiert, ohne Unterlaß, wie aus dem finstern Urgrund des Absolutums durch Streben nach Oben die Dinge in immer vollkommnern Gestalten hervorgehn, aus der Nacht sich das Licht gebiert, ein beständiges Werden, und Wachsen, ohne Anfang und Ende».

47 MdN, 208: «...Die andern [Philosophen] folgen den Fußstapfen Schellings, behaupten nämlich eine Art von sechstem Sinn zu haben, eine Anschauung des Absolutums und schauen damit lange Historien an, die das Dasein der Welt enträthseln sollen; aber Jeder hat seine eigne: und Schelling hat die seine drei Mal von Grund aus geändert...» $C f$. también una alusión a «largas historias» basadas en intuiciones del absoluto -pero sin mención de Schelling-en TgV, 420, y antes en KKP, 618 (1818).

$48 \mathrm{Al}$ comienzo de la «Metafísica de las costumbres» (equivalente al lib. IV de W I), Schopenhauer mantiene aún una breve nota remitiendo al texto de W I acerca del «filosofar histórico». Cf. MdS, 50. Sin embargo, el hecho de que el pasaje de W I quede reducido a esa breve anotación significa, casi con toda seguridad ( $c f$. otras referencias similares en las Vorlesungen), que a Schopenhauer le parece prescindible.

49 Cf. W II, cap. 17, 203ss (en p. 205 hay una nueva alusión a las filosofías históricas -sin emplear el término ni mencionar ejemplos-), y P I, 72s, donde se recupera parte del fragmento de 1834 del que en seguida hablamos, pero $\sin$ la mención de Schelling.

$50 \quad$ HN IV-1, 181 (Pandectae, $\mathrm{n}^{\circ}$ 86, 1834): «In Schellings Abhandlung von der Freiheit habe ich die Stellen angemerkt, wo sein Exempel nicht aufgeht».

51 Claro que Schopenhauer puede referirse además a cualquiera de las otras críticas que anotó en el ejemplar: quizá precisamente dándose cuenta de ello, Hübscher ha optado (en HN IV-1, 340, nota al fragmento de 1834 del que hablábamos) por remitir, para la frase citada de Pandectae, no sólo a las notas al ejemplar (HN V, 147s) sino también a las de 1812 (HN II, 312-314), una torpe decisión a nuestro modo de ver, ya que Schopenhauer en 1834 se está refiriendo, con bastante claridad, a una acción reciente. 
con ese sistema, sólo habría dos alternativas, o un dualismo absoluto o una identidad absoluta que conduciría, según el propio Schelling, a «consecuencias absurdas» -el bien y el mal serían lo mismo, etc.-; como solución aparece el famoso «Urgrund o, más bien, Ungrund», mediante el cual se introduce el concepto de indiferencia, que ha de verse como plenamente distinto de aquella identidad $^{52}$. Es aquí donde

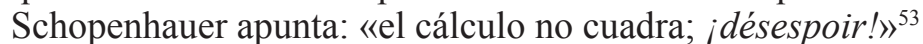

La combinación de esa anotación con el fragmento de 1834 permite, por lo demás, una datación muy plausible de las notas al ejemplar del Freiheitsschrift que recoge Hübscher en el vol. V del Nachlass ${ }^{54}$ entre en torno a dicha fecha y $1837^{55}$. No nos detendremos en el examen de esas notas: se trata de apuntes breves, de una o dos líneas, que resultan un tanto crípticos aunque en algún caso anuncian temas que después aparecerán en las Werke del filósofo: por ejemplo, con un tono harto deteriorado en comparación con las notas juveniles de 1812, se retoma la acusación de imitar a Böhme ${ }^{56}$, muy endurecida, a la cual viene a sumarse otra nueva: la de intentar hacer pasar la teoría kantiana del carácter inteligible como propia, cosa que se sugiere en estas notas por primera $\mathrm{vez}^{57}$. El reconocimiento, en dos ocasiones, no exactamente de una influencia, pero sí de un «presagio (Vorspuk) de mí»» ${ }^{58}$, no suaviza demasiado el tono conjunto de las notas. Las razones del deterioro de la relación con Schelling (no sólo el de 1809), que por lo demás nunca fue demasiado buena, no son claras, pero seguramente puede relacionarse con la «campaña» de Schopenhauer contra los «profesores» que se gesta desde el comienzo de la década de 1830 en los manuscritos y empieza a plasmarse en publicaciones a partir de 1836.

De esas publicaciones, la primera que contiene referencias expresas al tratado de Schelling es Los dos problemas fundamentales de la ética (1841): de las dos memorias que incluye el libro, la primera (Sobre la libertad de la voluntad) presenta lo que parece querer ser una crítica definitiva del Freiheitsschrift. Ello viene exigido hasta cierto punto por el mismo tema de la memoria -la libertad-y la presencia de una sección consagrada a los «Predecesores» ${ }^{59}$. Antes de hablar sobre el libro en

52 Cf. Schelling, SW VII, 406. Esta distinción, introducida en 1809, de dos términos que habían sido equivalentes en la época del sistema de la identidad ha sido notada, por ejemplo, por F. Duque, op. cit., p. 309 y nota 642; este autor entiende que con «identidad» se alude a la resolución de oposiciones, mientras que, ahora (en 1809), la «In-diferencia» más bien apunta a que aquéllas se encuentran (sin conciliación) en el Urgrund.

53 HN V, 148, comentario a la p. 497 (=SW VII, 406) de Phil. Schriften: «Das Exempel geht nicht auf, Désespoir!» De «desesperación»se habla también en el comentario a p. 495 («Gefasel der letzten Verzweiflung geht in Wahnwitz über»). Recuérdese que la palabra aparecía también en el pasaje sobre el «filosofar histórico» de W I, 322s: la doctrina del continuo devenir, del Urgrund, etc. surgía de la «desesperación» por la esterilidad de las vías intentadas antes (el sistema de 1804 y las «cosmogonías» anteriores).

$54 \mathrm{HN} \mathrm{V}, 147 \mathrm{~s}\left(\mathrm{n}^{\circ}\right.$ 485), anotaciones a Phil. Schriften, Bd. 1; corresponden al Freiheitsschrift los comentarios a las páginas 406-495 (Hübscher reproduce todos los comentarios al volumen sin especificar dónde comienza cada uno de los cinco tratados que reúne).

55 Hübscher no data las anotaciones al ejemplar de Phil. Schriften excepto mediante el criterio vago del útil de escritura empleado en ellas (tinta / lápiz, que valen, respectivamente, por «temprano» y «tardío»). Pero, dado que el tratado de 1809 es mencionado numerosas veces en las dos memorias reunidas en BGE, lo que apunta a una relectura reciente de Freiheitsschrift, habría que datar esas anotaciones de HN V, ya en torno a 1834 (fragmento de Pandectae),ya, como tarde, hacia 1837 (fecha de inicio de la redacción de la primera de las memorias).

$56 \quad \mathrm{HN} \mathrm{V}, 147$, comentarios a las pp. 435 y 497.

57 HN V, 147, comentario a la p. 465.

$58 \mathrm{HN}$ V, 147, comentarios a pp. 436 y 455. En ambos casos escribe Schopenhauer: «Vorspuk von mir».

59 Secc. IV («Vorgänger») de la primera memoria, en BGE, 63ss. Unas páginas antes (BGE, 54) hay una nota donde ya se nombra el Freiheitsschrift con relación a la cita de Veleyo Patérculo en la p. 478 de la edic. de 1809 
general y acerca de lo que aporta al tema del que trata la memoria, Schopenhauer vuelve a mencionar, como en 1813 , el pasaje donde se expone la teoría kantiana del carácter empírico: esta vez, lejos del tono laudatorio de la disertación, lo llama secamente una «paráfrasis aclaratoria» que puede servir para facilitar a muchos la compleja exposición kantiana; pero sobre todo pone énfasis en reprochar a Schelling que «no expresa claramente» el origen kantiano de la teoría, lo que se prestaría a que los lectores se la adjudiquen a Schelling, de lo cual Schopenhauer encuentra un ejemplo en un libro de J.E. Erdmann de 1837 a la vez que aduce algunos argumentos que presuntamente probarían que dicho proceder en Schelling fue obra de intención ${ }^{60}$. Es después de esta cuasi-acusación de plagio cuando Schopenhauer emite su juicio sobre la obra:

Aparte de esta paráfrasis de pensamientos kantianos, esas "Investigaciones sobre la libertad" no contienen nada que pudiera servir para procurarnos aclaraciones nuevas o fundamentales sobre la misma. Esto se anuncia ya en el mismo comienzo, mediante la definición según la cual la libertad es "una facultad de lo bueno y lo malo". Para el catecismo, una definición tal puede ser idónea: pero en la filosofía con eso no se ha dicho nada y por consiguiente tampoco se puede comenzar nada. Pues lo bueno y malo están muy lejos de ser conceptos simples (notiones simplices), claros en sí mismos, que no necesiten ninguna explicación, constatación y fundamentación. En general, de ese tratado, tan sólo una pequeña parte trata sobre la libertad: su contenido principal es más bien un informe detallado sobre un dios con el que el señor autor delata íntima familiaridad, pues incluso nos describe su nacimiento; sólo que es de lamentar que no diga ni una palabra sobre cómo ha llegado a esa familiaridad. El comienzo del tratado crea un tejido de sofismas cuya insipidez reconocerá todo el que no se deje intimidar por el atrevimiento del tono ${ }^{61}$.

A renglón seguido Schopenhauer procede a referirse al texto de Schelling como uno de tantos «productos semejantes» con los que los postkantianos habrían sustituido los conceptos claros y la investigación honesta por el método de «imponer, aturdir, mistificar, arrojar al lector arena a los ojos mediante toda clase de artificios ${ }^{62}$. Aquí, pues, sale a la luz la actitud que se sugería en los comentarios al Freiheitsschrift recogidos en $\mathrm{HN}$ V: nos hallamos en el periodo de máxima animosidad antischellingiana, ligada a los comienzos de la particular «guerra» pública de Schopenhauer contra los «profesores de filosofía». Ese tono caracteriza también a la única referencia al tratado de Schelling que se halla en la segunda memoria, Sobre el fundamento de la moral, en la que se repite y radicaliza la acusación de plagio de la doctrina de Kant de la libertad inteligible ${ }^{63}$. Vemos, pues, que incluso en el texto donde por fin parece proponerse ofrecer un juicio definitivo sobre el texto de Schelling, a pesar de que el contexto facilita especialmente el enfoque ético del

(= SW VII, 393), la traducción de la cual que da Schelling estaría «algo falseada para sus fines».

60 BGE, 82-84. Al final del pasaje, en la $2^{\text {a }}$ edic. (1860) se añade aún una frase sobre la imitación de Böhme. De los argumentos relativos al «plagio» de Kant, poco sólidos a nuestro modo de ver, prescindiremos aquí, si bien habremos de volver a la cuestión de estas acusaciones de plagio.

${ }^{61}$ BGE, 84. En esta y las traducciones de pasajes de BGE que siguen empleamos la versión de Pilar López de Santa María (Los dos problemas fundamentales de la ética, Madrid: Siglo XXI, 1993), a menudo con modificaciones. Sobre la observación final sobre la «red de sofismas» del «comienzo del tratado», $c f$. el boceto en HN V, 148 (última anotación a Phil. Schriften, escrita en el interior de la contraportada).

$62 C f$. BGE, $84 \mathrm{~s}$.

${ }^{63} C f$. BGE, 176. 
asunto, justo de las implicaciones éticas del tratado Schopenhauer no comenta nada, al margen de rechazar que Schelling comience por una definición de la libertad como «una facultad de lo bueno y lo malo» sin definir a su vez estos conceptos, lo que propiamente es una objeción metodológica; en cambio, nuestro filósofo insiste en centrar su crítica en que «el contenido principal» de la obra consiste en «un detallado informe» sobre Dios: con ello se prosigue la línea crítica iniciada en 1819 en la que el foco aparente de la discusión es puramente el ontoteológico.

De modo similar, ese enfoque de la crítica es el que domina en las alusiones al tratado sobre la libertad de Schelling, varias de ellas tácitas, que se encuentran en la segunda versión (1847) de la tesis doctoral Sobre la cuádruple raíz del principio de razón suficiente: por una parte, Schopenhauer ironiza sobre la peculiar recuperación del argumento ontológico cartesiano y spinoziano en el escrito de Schelling ${ }^{64}$; por otra, alude al tratado de forma paródica al mentar la «construcción a priori» de un «proceso vital» por el que Dios «a partir de sí impulsó y en cierto modo engendró el mundo» ${ }^{65}$, y, en otro lugar, el «nacimiento de Dios desde su tenebroso Grund, o Ungrund, a la Jakob Böhme ${ }^{66}$. Por cierto que en el primero de los pasajes nombrados Schopenhauer aprovecha para publicar la acusación de plagio de Böhme, retomando el tema que había surgido ya en sus anotaciones de 1812 y añadiendo ciertas precisiones anotadas en sus comentarios de los años 1830 al ejemplar ${ }^{67}$.

Los pocos pasajes de la última publicación de Schopenhauer, Parerga y paralipómena, que hacen referencia al Freiheitsschrift ofrecen cierto contrapeso a la actitud de animosidad característica de los años 1820-1840, pues en el libro hallamos cierta revaloración positiva, aunque ni mucho menos incondicional, de este y otros escritos de Schelling ${ }^{68}$. Por una parte, en el «Apéndice» del «Bosquejo de una historia de la doctrina de lo real y lo ideal» hay un par de alusiones: en la primera, cuando en cierto lugar Schopenhauer elogia algunos méritos de Schelling, uno de ellos sería el haber amalgamado las doctrinas de Plotino, Spinoza, Böhme, Kant y la

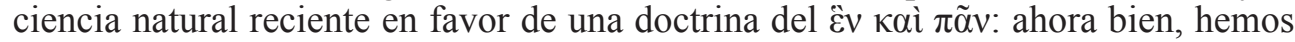
de entender que el lugar preciso donde «Böhme» es introducido en la «amalgama

${ }^{64} C f$. SzG, 16. Schopenhauer presenta la versión del Schelling de 1809 del argumento ontológico (para cuya peculiar reformulación $c f$. Schelling, SW, VII, 357s) como un capítulo de una historia de dicho argumento en la que le precedieron Descartes y Spinoza. Schopenhauer ya había comentado el asunto en un añadido de fecha incierta -podría ser hasta de la década de 1840- a un fragmento de 1814: cf. HN I, 191, n 308, Zusatz tachado.

${ }^{6} \mathrm{Cf}$. $\mathrm{SzG}, 111 \mathrm{~s}$. El pasaje se refiere de forma tácita a diversos postkantianos; a Schelling en concreto se le alude en la p. 112 al mencionar que la facultad trascendente denominada Vernunft por los postkantianos, entre otras cosas, «auch die Art und Weise a priori konstruirt, wie er [= Gott] die Welt geschaffen, oder, wenn das zu trivial seyn sollte, wie er sie, durch einen mehr oder minder nothwendigen Lebensproceß, aus sich heraustrieben und gewissermaaßen erzeugt (...) habe». El pasaje contiene una alusión al hegeliano «sich entlassen» de la Idea a la Naturaleza, que se contrapone expresamente a esa doctrina del «proceso vital», la cual, por eliminación, tiene todas las trazas de aludir al Freiheitsschrift, como indican incluso algunos giros empleados.

${ }^{66} \mathrm{SzG}, 123$ : «...das Entstehn Gottes aus seinem finstern Grunde, oder Ungrunde, à la Jakob Böhme...»

${ }^{67} \mathrm{Cf}$. SzG, 16s: Schelling habría tomado «toda la fábula» del Urgrund del Gründlicher Bericht vom irdischen und himmlischen Mysterio (es decir, del Mysterium Pansophicum: en las notas de 1812 remitía, en cambio, al

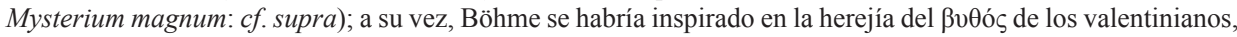
para la cual remite a Ireneo, contr. haeres., lib. I, 1. Este pasaje de SzG, que hay que tener por el definitivo de Schopenhauer sobre el tema, tiene su esbozo en el comentario a la p. 497 de Phil. Schriften (= SW VII, 406) en HN V, 148, donde informa además de que la cita de Ireneo la halló en el Oupnek'hat, vol. I, p. 562. Como hemos dicho en la nota 11, los intérpretes de Schelling suelen dar por bueno este reproche de Schopenhauer.

68 Aparte de lo relativo al tratado de 1809, encontramos en la obra menciones favorables de Ideen... y Weltseele en P II, $\S 77$, pp. 118 y 120 respectivamente, y un decidido encomio de la Naturphilosophie en P I, 26s (en texto añadido en la $2^{\mathrm{a}}$ edic., de 1862). 
ecléctica» de la filosofía schellingiana es el tratado de 1809: por lo que en esta ocasión, de modo algo paradójico, la imitación o incluso plagio de Jakob Böhme se contempla como un aspecto favorable, digno de aplauso en cierto sentido, de la labor de Schelling ${ }^{69}$. Un par de páginas después, tras la crítica de la Naturphilosophie como reducción de la metafísica a una física, Schopenhauer cita, como contraste, el Freiheitsschrift, que, a diferencia de otros proyectos previos de Schelling, habría sido «un auténtico ensayo metafísico», si bien en conjunto sería «una mera pieza de fantasía, un conte bleu» ${ }^{70}$. Aun lejos de ser el mayor elogio imaginable, el reconocimiento de un «auténtico ensayo metafísico» en el tratado resulta, después de cuanto llevamos visto, una inesperada concesión que, propiamente, Schopenhauer, con lo que ha dejado escrito sobre el tema, no nos ayuda demasiado a entender: pues, hasta aquí -y no nos espera ninguna gran sorpresa- casi el único aplauso decidido de algún pasaje concreto de la obra fue el de la exposición de la doctrina kantiana de la libertad inteligible, y las últimas noticias eran más bien que el aplauso era retirado debido a la sospecha de plagio. Este repentino reconocimiento de un «auténtico» intento de elaborar una metafísica -por lo demás, fallido: una mera «fantasía»-, a falta de aclaraciones ulteriores, siempre nos lo podemos explicar por el espíritu hasta cierto punto común de la metafísica de Schopenhauer con el tratado de Schelling, conexión que se ha señalado con cierta frecuencia ${ }^{71}$. Pero, decimos, el propio Schopenhauer no da ninguna pista clara en este sentido. Lo que sí hace es referirse, en otro lugar de los Parerga, precisamente a la mencionada conexión, que algunos críticos habían sugerido, según él mismo indica, en alguna recensión temprana ${ }^{72}: \sin$ negar la semejanza -y mencionando además a Fichte-, Schopenhauer la califica de Vorspuk (el mismo término empleado en las notas al tratado en HN V) y la explica por la fuente e influencia común, la filosofía de Kant, y protesta además por el excesivo valor que se da a tales coincidencias puntuales, sin tener en cuenta el papel que desempeñan esas anticipaciones, «presagios» $\mathrm{o}$ «augurios» como los llama, en el contexto del sistema del autor «predecesor». Volveremos a este asunto; de momento digamos que en el pasaje hay al menos cierta concesión, aun de mala gana, al valor de la filosofía de estos autores, en el reconocimiento de ciertas coincidencias -sólo cita expresamente la frase «Wollen ist Urseyn» del tratado de 1809, pero él mismo sugiere que hay otras--. En los Parerga, en suma, se produce una cierta reevaluación del Freiheitsschrift que lleva a Schopenhauer a conceder al libro algún mérito, cosa que, según hemos podido ver, no sucedía en absoluto desde aquella mención laudatoria, en la disertación de 1813, del pasaje sobre la doctrina kantiana de la libertad inteligible. Esto no significa, naturalmente, que se invaliden las críticas hasta este momento dominantes.

$69 C f$. P I, 26s. «Eclecticismo» y «amalgama» son dos términos con que Schopenhauer describe, en el pregnante pasaje, la filosofía de Schelling en conjunto, como ya lo hiciera en el no menos pregnante pasaje -pero en el que la mención de la «amalgama» de Schelling no es tan decididamente positiva- de BGE, 269. En ambos lugares aparece la misma lista de elementos «amalgamados» (Spinoza, Böhme, Kant, etc.).

70 P I, 29: «Als (...) Schelling später selbst merkte, daß die metaphysischen Probleme sich nicht durch Machtsprüche abweisen lassen, lieferte er einen eigentlichen metaphysischen Versuch, in seiner Abhandlung über die Freiheit, welche jedoch ein bloßes Phantasiestück, ein conte bleu, ist, daher es eben kommt, daß der Vortrag, so oft er den demonstrirenden Ton annimmt (z.B. S. 453 ff.), eine entschieden komische Wirkung hat». El pasaje del Freiheitsschrift al que remite Schopenhauer, pp. 453ss de Phil. Schr. (1809), equivale a SW VII, 374-376. En las notas al ejemplar (HN V), hay un comentario muy similar, pero acerca de otra página, la 484; en cambio, el lugar citado en P I no es comentado ni en las notas de HN V ni en las de HN II.

71 Cf. infra $(\$ 5)$ para algunos ejemplos de intérpretes que han establecido la conexión.

72 P I, 142 («Fragmente zur Geschichte der Philosophie», § 14). 
Las últimas menciones o alusiones de Schopenhauer al tratado sobre la libertad confirman en efecto tanto aquellas críticas como su acento en lo ontoteológico: en particular, un pasaje añadido en la última edición (1859) del segundo tomo de Die Welt donde se habla de quienes «pretenden conocer las razones últimas -es decir, las primeras- de las cosas, o sea, un proto-ser (Urwesen), absolutum o como se le quiera llamar, así como el proceso, las razones, los motivos o lo que sea, a resultas de los cuales el mundo surge de él, o brota, o cae, o es producido, puesto en la existencia, "despachado" y mandado a paseo» ${ }^{73}$. Con esta enésima reformulación de la crítica a las «historias» $\mathrm{o}$ «cuentos» del absoluto se alude no sólo a Schelling en diversas etapas -la de 1804 como mínimo, además de la de 1809-, sino también a otros filósofos (Hegel, en concreto ${ }^{74}$ ); pero la mención del Urwesen, término poco más o menos sinónimo de Urseyn en el tratado de Schelling, es inequívoca ${ }^{75}$. En la misma dirección apunta un fragmento de 1853 en el que se repite la asociación, establecida en $1814^{76}$, del Freiheitsschrift con las «teorías creacionistas», seguramente debida a la determinación de Dios como fundamento, Grund, del mundo ${ }^{77}$.

Termina con esto nuestro recorrido con vistas a esclarecer la posición de Schopenhauer frente al tratado de la libertad de Schelling a través de su evolución $\mathrm{y}$, a la vez, ofrecer un muestrario de los materiales disponibles sobre el asunto y los problemas que plantean. Recapitulando, hemos podido ver cómo Schopenhauer no simpatiza apenas con el libro ni siquiera en su primer contacto con él: en las notas de 1812, la actitud es crítica pero también distante; no formula en ese momento inicial ningún juicio decisivo, pero apunta ya su rechazo hacia la manifiesta imitación de Böhme, así como esboza una crítica al fatalismo implícito en el sistema que allí se expone. Poco después, denomina a éste por primera vez «cuento». La fuente principal de este rechazo se explicita en algunos fragmentos del periodo de preparación de Die Welt: se trata de la teoría trascendente de la salvación, soteriología, que pone su meta en un futuro histórico. Esto explica que la breve polémica con las «filosofías históricas» que se publica en Die Welt -polémica que se concentra exclusivamente en Schelling- se halle al comienzo del libro IV y no en otro $\operatorname{lugar}^{78}$, a pesar de que en las ironías sobre esas «filosofías del devenir» se enfatice en aspectos metafísicos o teológicos, como el «autoparirse» de Dios, tema en el que se insiste también en las citas referentes al libro inmediatamente posteriores a Die Welt. Seguramente es

73 W II, 206 (pasaje añadido en 1859). Traducción de P. López de Santa María, algo modificada.

74 Con el verbo «entlassen» (despedir, despachar, dar de alta, soltar...) como «explicación» de la relación DiosMundo, Schopenhauer alude a Hegel (tanto en W II 206 como en SzG, 112), tomando el término de Enz., § 244, lugar donde se emplea para expresar el tránsito de la Idea (culminación de la Lógica) a la Naturaleza.

$75 C f$. el empleo de Urwesen en SW VII, 337 (los traductores españoles citados vierten «ser originario», exactamente tal como hacen con Urseyn: $c f$. trad. cit., p. 114s). Urwesen es, por lo demás, un término utilizado por Schelling en su «etapa positiva». Sin embargo, parece muy improbable que en la cita se aluda al Schelling «positivo», del cual, aunque algo, Schopenhauer conoció poco.

$76 \quad C f$. HN I, 78s, n 126 (1814), citado supra.

77 HN IV-2, 10, Senilia, nº 29 (1853): «Die von den Neuplatonikern, Skotus Erigena, Jakob Böhm und Schelling nebst Schellingianern gegebenen Schilderungen und Konstruktionen der Entwickelung des Absoluten, des Gottes oder dgl. zur Entstehung der Welt (...) sind eigentlich heimliche Versuche aus Nichts Etwas zu machen. Diesen Demonstrationen liegen eigentlich verdeckt gehaltene Naturgesetze zum Grunde, die Solches jedoch gar nicht erlauben würden».

${ }_{78} C f$. en HN I, 78s y 168 , los fragmentos $\mathrm{n}^{\circ} 126 \mathrm{y} \mathrm{n}^{\circ} 274$, citados arriba. El pasaje de W I, 322s., del $\S 53$, no explicita el trasfondo ético de la discusión; sin embargo, el lugar donde se ubica lo implica de forma bastante clara. El hecho de que, imitación de Böhme aparte, éste sea el caballo de batalla principal en las anotaciones y fragmentos que van de 1812 a 1816 apoya esta interpretación bastante sólidamente, creemos. $C f$. el $\S 4$. 
en el mismo sentido en el que mejor podemos interpretar la cuestión, introducida a mediados de los 1830, del «cálculo que no cuadra» en el tratado de 1809. La calificación de la obra como un «cuento», palabra que viene a concentrar el conjunto de las críticas doctrinales a la misma, surge inicialmente en el contexto de una discusión de fondo que se centra en los aspectos éticos y soteriológicos: esto resulta harto evidente a la vista de varios de los principales fragmentos de la época estudiantil, y, decíamos, ésta sigue siendo la polémica de fondo en el pasaje de Die Welt (§ 53) sobre las «filosofías históricas»: aquí, sin embargo, como en otros lugares donde se alude al Freiheitsschrift como «cuento del absoluto» o expresiones equivalentes, el énfasis se pone más bien en el aspecto teológico-cosmogónico, con lo que se sugiere al lector la implicación inmediata de que nos hallamos ante una nueva ontología dogmática que cae en los errores ya refutados por la filosofía trascendental kantiana. Sin negar, desde luego, que esto último corresponda también a la opinión auténtica de Schopenhauer, y a pesar del aparentemente completo desplazamiento del foco de la polémica en esa dirección, según nuestra interpretación sigue siendo el debate ético-soteriológico el que funge como primum mobile de estas críticas. Como trataremos de mostrar, aunque ciertamente ese debate queda, sobre todo en la obra publicada, muy enterrado, no es necesario apenas plantear conjeturas para defender dicha interpretación.

\section{Para la interpretación de las principales objeciones de Schopenhauer al «tratado sobre la libertad»}

Las críticas al Freiheitsschrift presentes en la obra publicada de Schopenhauer, en realidad más bien parodias e ironías, se dirigen casi en su totalidad, como se ha visto, a denunciar el contenido del tratado como una metafísica dogmática a la manera de aquellas que Kant se había esforzado por deslegitimar. Debido en parte al estilo satírico con que las presenta, Schopenhauer no ofrece en ningún caso argumentos desarrollados contra dicha forma criticada de metafísica en el tratado de Schelling; cabe suponer que espera que el lector se remita por sí mismo a la crítica kantiana así como a otros pasajes del propio Schopenhauer donde sí se aducen argumentos acerca del concepto del absoluto, el abuso del principio de razón y otros similares. Por estas mismas razones, porque el mismo Schopenhauer prescinde de argumentar y porque podemos esperar con él que el lector realice él mismo dichas conexiones, nos eximiremos de intentar aquí enriquecer esas breves alusiones paródicas e irónicas en las que consiste la crítica principal al tratado de 1809 en la obra publicada del filósofo. La cuestión que sí que nos interesa esclarecer es la de hasta dónde llega realmente ese desplazamiento del centro de la polémica, que inicialmente se hallaba más bien en la diferencia fundamental de las posiciones de los dos autores respecto al tema de la soteriología. Por una parte, no puede negarse que para Schopenhauer realmente ese «nuevo» enfoque ontológico de la crítica cobra especial relevancia a partir de los años inmediatamente posteriores a la publicación de Die Welt, y no se trata, por acaso, de un «gesto» o «retórica» de cara al lector con vistas, pongamos, a desprestigiar el tratado de Schelling mediante el recurso cómodo a las debilidades del mismo desde un punto de vista kantiano: dicho enfoque, en efecto, no sólo se encuentra en la obra publicada, sino también en fragmentos de uso personal de Schopenhauer, tanto de la época que siguió a la edición de la obra principal como de 
los últimos años ${ }^{79}$. Por otra parte, lo que llama la atención en este desplazamiento es el hecho de que, a la vista de los materiales de los que disponemos, es prácticamente absoluto. ¿Qué vestigios quedan en este periodo, que va desde 1819 hasta los últimos años de Schopenhauer, de aquel inicial Triebfeder de su rechazo de las doctrinas del Freiheitsschrift? Y, si los hay aún, ¿puede decirse todavía que la polémica principal con el tratado, aunque quede oculta en el trasfondo, sigue siendo la misma?

Respondamos a la primera cuestión. Lo que queda de la posición inicial, dominante, según vimos, desde 1812 hasta, aunque de manera ya bastante soterrada, el $\S 53$ de Die Welt, es, en ese segundo periodo en el que toma el papel principal la cuestión del dogmatismo ontoteológico, más bien poco, y no del todo explícito, pero podemos afirmar que está ahí sin tener que -como decíamos arriba- forzar los materiales.

1) En primer lugar, tenemos aquella aseveración orgullosa de Schopenhauer en 1834 por la cual aseguraba haber anotado en su ejemplar del Freiheitsschrift «los pasajes donde su cálculo no cuadra ${ }^{80}$. Como dijimos, cuando vamos a buscar entre los comentarios al tratado que se hallan en $\mathrm{HN} \mathrm{V}$, de las prometidas anotaciones apenas encontramos una que corresponda de forma clara a lo que Schopenhauer dice: de cierta página del libro, escribe que «el cálculo no cuadra; désespoir!» ${ }^{81} \mathrm{En}$ ese lugar, Schelling confiesa las debilidades y contradicciones a las que se llega mediante los conceptos empleados hasta ese momento en la argumentación del tratado -en concreto, la «identidad» absoluta como conciliación de la concepción del ser en cuanto fundamento y del ser en cuanto existente-, problema para resolver el cual introduce por una parte el Urgrund o Ungrund y por otra el concepto de «indiferencia absoluta» (que aquí se distingue de aquella «identidad»): hasta aquí, parece que con la mención del «cálculo que no cuadra» seguimos en el terreno de las críticas a los aspectos ontoteológicos del tratado. Pero no es necesario tirar demasiado del hilo para encontrar las implicaciones de un debate principalmente ético que se ocultan detrás de estas citas:

a) El propio Schelling destaca, entre esas consecuencias indeseadas de la debilidad del sistema a salvar, el que con dicha flaqueza se caería en una identidad del bien y el mal con la que se echaría a perder la explicación del origen y del conflicto de uno y otro ${ }^{82}$.

b) En el fragmento de 1834, en las líneas que preceden a la alusión al tratado sobre la libertad, Schopenhauer habla de diversos ejemplos de sistemas filosóficos en los que «la cuenta no sale»: materialismo, teísmo, panteísmo. Los dos últimos no concuerdan, dice, con «los predominantes males físicos y morales» del mundo; en cuanto al materialismo, como lo que éste deja sin explicar apunta aquí la «conformidad a fin del mundo y el conocimiento» ${ }^{83}$, pero sabemos por otras vías que

79 Fragmentos tempranos con dicha orientación ontológica: HN III, 10, Reisebuch, $\mathrm{n}^{\circ} 32$ (1819); HN III, 87 (Foliant, n 37, 1821), citados unos párrafos arriba, además de todo lo relativo al «cuento» (ya desde 1812). Un ejemplo tardío: HN IV-2, 10, Senilia, $\mathrm{n}^{\circ} 29$ (1853), también citado supra.

80 HN IV-1, 181 (Pandectae, $\mathrm{n}^{\circ} 86,1834$ ).

81 HN V, 148, comentario a la p. 497 del Freiheitsschrift (= SW VII, 406).

82 Cf. Schelling, Freiheitsschrift, SW VII, 406.

83 HN IV-1, 181 (Pandectae, $\mathrm{n}^{\circ}$ 86, 1834): «...so z. B. diskordirt mit den materialistischen Systemen (welche die Gesetze der mit bloß mechanischen Eigenschaften ausgestatteten Materie zur Basis alles Daseyns machen und davon absehn daß sie bloß diese Vorstellung ist) vollkommen die Zweckmäßigkeit der Welt und die Erkenntniß; mit den theistischen und pantheistischen die überwiegenden physischen und moralischen Übel u.s.w.» 
la enemiga de Schopenhauer con el materialismo ante todo radica, asimismo, en sus implicaciones éticas ${ }^{84}$.

c) Y exactamente lo mismo que acerca del fragmento de 1834 puede decirse, además, del pasaje del segundo tomo de Die Welt donde se reformula el tema de la filosofía como «desciframiento» del «enigma» del mundo y los ejemplos de filosofías en las que tal desciframiento lleva a contradicciones o inconsecuencias. En esta ocasión, dichos ejemplos no son los mismos que los aducidos en 1834, pero los argumentos no están muy lejos: se mencionan esta vez, pues, el «optimismo leibniziano», que «contradice la evidente miseria de la existencia»; la doctrina spinoziana de la sustancia absolutamente necesaria, que se opone a nuestro asombro ante la existencia del mundo; el creacionismo de Wolff, que, al anular la aseidad de nuestra existencia, quita todo sentido a la responsabilidad moral que, sin embargo, sentimos con evidencia. Y, aunque esta vez no se menciona a Schelling en absoluto, sí que se vuelve a aludir a las «filosofías históricas» antaño representadas eminentemente por él, y esta vez subrayando más que en 1818 (W I, § 53) el trasfondo soteriológico de la crítica, pues se refiere a aquéllas como «la doctrina a menudo repetida de una evolución progresiva de la humanidad hacia una perfección cada vez más alta, o en general de algún devenir por medio del proceso del mundo» ${ }^{85}$.

Así pues, conforme a lo anterior, puede decirse con casi total rotundidad que el críptico reproche de 1834 al Freiheitsschrift de ser un «cálculo que no cuadra» se dirige en lo fundamental al sistema soteriológico que la obra plantea, que no consiste en otra cosa que en ese «devenir» o «evolución progresiva» hacia una creciente perfección, doctrina que, aun sin nombrar ya a Schelling, se menciona todavía en 1844 como ejemplo de «desciframiento» que no se ajusta a la experiencia ni a sus leyes. Vemos así cómo el que en los primeros años era el motor fundamental de la crítica de Schopenhauer no ha desaparecido en absoluto, a pesar de haber sido desplazado, al menos aparentemente, por la crítica de los aspectos metafísicos y teológicos del libro de Schelling.

84 Cf. W II, 194: «Sogar hinter dem an sich abgeschmackten, auch meistens boshaften Vorwurf des Atheismus liegt als seine innere Bedeutung und ihm Kraft ertheilende Wahrheit der dunkle Begriff einer solchen absoluten Physik ohne Metaphysik. Allerdings müßte eine solche für die Ethik zerstörend sein...»; WN, «Vorrede» de 1854, p. Xs («bestialidad moral» de los resultados últimos del «grosero y torpe materialismo»); SzG, 122 («... el materialismo, siempre al acecho, con su compañero el bestialismo...»); P II, 36s (ausencia de moral en el «naturalismo puro» o «física absoluta»); P II, 108 («esa idea de que el mundo tiene un significado físico, pero ninguno moral, es el error más desdichado, surgido de la mayor perversidad del espíritu»); P II, § 109, p. 214 («Daß die Welt bloß eine physische, keine moralische Bedeutung habe, ist der größte, der verderblichste, der fundamentale Irrtum, die eigentliche Perversität der Gesinnung...»). La polémica ética de Schopenhauer con el materialismo conecta, por cierto, y muy de cerca, con su polémica con la Naturphilosophie de Schelling. Así, en P I, 28, reprocha a ésta la pretensión de reducir a física la metafísica; en las notas (seguramente de los años 1830) a la Darlegung des wahren Verhältnisses der Naturphilosophie zu der verbesserten Fichte'schen Lehre, en la p. 16 (error del editor: realmente es la p. 18 = SW VII, 32s), al pasaje de Schelling «...den letzten Schritt... welchen die Vernunftwissenschaft getan hat, daß sie Naturphilosophie werde...», contesta Schopenhauer (HN V, 144): «also d.h. allen Philosophen zum Trotz wollen wir die Metaphysik zur Physik machen, oder vielmehr die Physik auf den Thron der Metaphysik setzten...» La misma expresión, «poner la física en el trono de la metafísica», aparece en el citado pasaje de W II, 194, contra el materialismo, pero sin mención de Schelling.

85 Cf. W II, 203ss, como Hauptstelle sobre la filosofía como «descriframiento» (Entzifferung). Las citas que damos en el texto proceden de la p. 205. El parentesco de las líneas relativas a «die oft wiederholten Lehre von einer fortschreitenden Entwickelung der Menschheit zu immer höherer Vollkommenheit» con la polémica con el «filosofar histórico» de W I, $\S 53$, se evidencia especialmente por el uso del argumento del tiempo infinito $a$ parte ante en el que ya habría sucedido todo cuanto puede suceder, argumento que aparece también en el $\S 53$ de W I, pero sólo en la $2^{\mathrm{a}}$ edición, como un pequeño añadido, que Schopenhauer habría introducido precisamente a raíz de este nuevo pasaje de W II (publicado a la vez, en 1844). 
2) Además de lo que se acaba de argumentar, tenemos, en segundo lugar, un indicio de la vigencia del debate soteriológico en otra cita tardía importante relacionada con el tratado sobre la libertad. Nos referimos al pasaje de los Parerga en el que Schopenhauer emite un ambiguo elogio del tratado: a diferencia de los anteriores intentos de Schelling -que serían los de la Naturphilosophie y el Identitätssystem y la doctrina de la «caída» del opúsculo de 1804-, el tratado de 1809 habría sido «un auténtico ensayo metafísico»; valor que se le reconoce a la obra para añadir a renglón seguido que, sin embargo, «es una mera pieza de fantasía, un conte bleu», que «cada vez que adopta el tono demostrativo... tiene un efecto decididamente cómico ${ }^{86}$. Prescindiendo de estas cláusulas, con las que se minimiza bastante el elogio, podemos preguntarnos qué tiene el tratado de 1809 que no tengan otros escritos previos de Schelling para merecer ese reconocimiento. Decíamos antes que en este lugar Schopenhauer no da ninguna pista sobre las razones de este elogio, que tan sólo tiene como precedente el aplauso, en 1813, de la exposición de la teoría kantiana de la libertad, aplauso que años más tarde se convierte en acusación de plagio y que por eso no parece un candidato muy plausible para explicar la repentina concesión de los Parerga. ¿En qué se funda ésta? ¿Qué tiene el tratado sobre la libertad que lo distinga, a ojos de Schopenhauer, para merecer ser llamado «un auténtico ensayo metafísico» a la vez que se niega tal categoría a las «etapas» anteriores de Schelling? Si nos ceñimos a los aspectos ontoteológicos de la obra en los que Schopenhauer se centra a partir de 1819 , el tratado, ciertamente, se distingue de la metafísica ofrecida en la época del sistema de la identidad y la Naturphilosophie, la cual, en el juicio de Schopenhauer -bien fundado en una serie de afirmaciones del propio Schelling- era más bien una metafísica que se reducía a física; sin embargo, no es tanta la distancia que lo separa del sistema de Filosofía y religión, donde igualmente se presenta una «historia», un «cuento» metafísico en el que el tiempo juega un papel trascendente. Ahora bien, el Freiheitsschrift tiene, entre otras peculiaridades, la de apelar a instancias irracionales, ciegas, cuya proximidad con la concepción de Schopenhauer de la «cosa en sí», la voluntad, se ha señalado confrecuencia; dicha apelación tiene como objetivo, además, explicar la existencia del mal, cuya realidad positiva se afirma en varias ocasiones en la obra, y cuyo origen se pone allí en la, por así decir, mismísima cuna del ser. Dicho de otra manera, se trata de una metafísica completamente atravesada por la consideración moral del mundo, inseparable de ésta, lo cual coincide exactamente con lo que Schopenhauer dice de su propia metafísica; y, además, en esa, por así decir, «metafísica moral» de Schelling, el mal no se despacha como una privación o falta de perfección (como todavía se venía a hacer en Filosofía y religión, obra que en lo demás tiene un estrecho parentesco con el tratado de 1809), sino que, de forma parecida a la de la metafísica schopenhaueriana, es reconocido en su realidad al extremo de ponerse en las raíces de lo existente ${ }^{87}$. Naturalmente, también este tratado es, como dice Schopenhauer, un conte bleu: por mediación del concepto optimista de la historia, el «cuento» termina felizmente con la victoria del bien en un futuro no demasiado lejano. Esto explica, desde luego, que el elogio de la obra por Schopenhauer no sea incondicional, pero el que el conjunto

86 P I, 29, citado supra.

87 Schopenhauer describe en WN, 143, su propia filosofía como un sistema en cuya base «ya se entreteje la existencia del mal con la del mundo»; y, en W II, 740, escribe (en polémica, por cierto, con el panteísmo, y por tanto de algún modo con Schelling): «Sólo en mí se reconocen honradamente los males del mundo en toda su magnitud: pueden hacerlo porque la respuesta a la pregunta por su origen coincide con la pregunta por el origen del mundo» (trad. de P. López de Santa María). 
del tratado no presente ese aire optimista del $\pi \alpha ́ v \tau \alpha \kappa \alpha \lambda \grave{\alpha} \lambda i ́ \alpha v$ que sí caracteriza a otras versiones de la metafísica schellingiana (incluido Filosofía y religión) es lo que se halla a la base, con toda plausibilidad, del elogio de los Parerga, junto a las mencionadas similitudes con la metafísica del propio Schopenhauer.

En suma, como la explicación más plausible del ambiguo elogio al Freiheitsschrift proponemos la índole moral de la metafísica que el escrito presenta, así como son los resultados, digamos, «optimistas» de esa metafísica los que, consideramos, se hallan a la base de las cláusulas por las que Schopenhauer restringe y mitiga su alabanza. Tenemos, pues, según esto, una segunda muestra de la época tardía (aunque más indirecta, y por tanto más débil que la anterior) de cómo para Schopenhauer el contenido moral de la obra sigue siendo fundamental en su relación con el libro de Schelling, a pesar de que, a partir de 1819, sean las críticas de orientación ontoteológica las que dominan en sus pasajes, publicados y privados, acerca del tratado. No hemos hallado otras citas tardías de Schopenhauer que podamos traer en defensa de dicha tesis, pero esperamos que el lector considere plausible, con nosotros, la interpretación, en el sentido indicado, de los dos importantes pasajes comentados, el fragmento de 1834 sobre el «cálculo que no cuadra» (junto a otras citas que se relacionan con él) y el breve elogio del tratado en los Parerga.

3) $Y$ en favor de esta interpretación podemos añadir todavía un indicio más, que nos permite adicionalmente establecer un puente entre los dos diferentes focos de la crítica de los que venimos hablando. Nos referimos al empleo de las expresiones «cuento», «historias», etc., con las que ocasionalmente Schopenhauer hace referencia sarcástica al contenido de la obra de Schelling, y que se presentan con preferencia en el segundo foco, esto es, en las críticas «metafísicas» en las que en apariencia ha desaparecido el debate soteriológico. Pues bien, por más que esto último -el desplazamiento del foco de las críticas- sea innegable, puede defenderse que el empleo de aquellas expresiones y otras similares justo apunta, como la del conte bleu empleada en el pasaje de los Parerga, a la perspectiva moral-soteriológica que caracteriza al tratado de Schelling: ¿Por qué llamar al sistema metafísico de esta obra un «cuento», si no es por ser un relato con, precisamente, un «final feliz»? En cuanto a las «largas historias», ciertamente puede decirse que el tratado burlado con dicha expresión ofrece una, por así decir, «historia del ser», que puede considerarse desde sus aspectos teológicos y cosmológicos -como lo hace Schopenhauer a partir de 1818-, pero ante todo, si ese tratado ofrece una «historia», es en la medida en que presenta una versión de la teodicea en la cual es justamente la historia, la historia universal humana, la que posibilita, para Schelling, una perspectiva soteriológica, una final victoria del bien sobre el mal que debemos esperar de los tiempos por venir. De manera que, incluso tras el desplazamiento del foco de la polémica, expresiones como las citadas delatarían todavía, conforme a lo dicho, la persistencia del trasfondo del debate soteriológico, por más que éste ya no se explicite en los textos tardíos. Si este último argumento supone tal vez forzar algo más la interpretación ${ }^{88}$, por lo menos creemos que los dos anteriores la justifican de forma plausible y suficiente.

88 Que, por ejemplo, sea esencial y característico del «cuento» el tener un «final feliz» tiene su plausibilidad, pero no es necesariamente así; para explicar el sarcasmo, basta la naturaleza de relato, de sucesión de acontecimientos. Así, por ejemplo, en las ocasiones en que Schopenhauer habla de un «cuento» de Fichte, no parece desempeñar ningún papel la perspectiva soteriológica de la filosofía práctica de éste, sino que se alude ante todo a la exposición de la conciencia como un proceso, o, dicho de otra manera, al método genético deductivo. Tan sólo la expresión conte bleu que aparece en la cita de P I, 29, implica inequívocamente aquella característica de los cuentos que, por lo demás, ni mucho menos es universal. 


\section{Influencias y plagios}

En lo que precede, nos hemos centrado en el estudio de los materiales para esa crítica del tratado de 1809 de Schelling que Schopenhauer tan sólo expuso de forma fragmentaria y cuyo análisis e interpretación constituye el asunto principal de este artículo. Hasta donde nosotros sabemos, se ofrece aquí por vez primera un estudio completo y exhaustivo de dichos materiales, pues, aunque podríamos citar algunos autores que ya prestaron menor o mayor atención al tema de la relación de Schopenhauer con el Freiheitsschrift -de forma eminente, Xavier Tilliette-, éstos siempre se conformaron con una visión parcial de la polémica, prescindiendo, además, de buscar una comprensión global de la misma. Conocer ésta, decíamos en la introducción, debería ser un requisito -no el único, por cierto- a la hora de entrar en la manida cuestión de la influencia del tratado de Schelling sobre la metafísica de la voluntad de Schopenhauer. El tema de la influencia es, por cierto, una de las vertientes de su discusión particular con Schelling, como ya hemos apuntado al revisar de formar más o menos cronológica los escritos, publicados e inéditos, de nuestro filósofo, y al que queremos todavía prestar atención, si bien de manera breve y a modo de complemento.

Vimos, pues, que en los comentarios de Schopenhauer al Freiheitsschrift que se recogen en $\mathrm{HN}$ V, de la década de 1830, irrumpía por primera vez el reconocimiento, no exactamente de una influencia de Schelling, pero sí de algo así como una «anticipación» de doctrinas de la metafísica de Schopenhauer. El término preciso que emplea éste, y en dos ocasiones, es Vorspuk, vocablo que traduciremos por «presagio» ${ }^{89}$. ¿Qué supone, después de cosa de quince años sin referirse al tratado de Schelling y en un momento -la década de 1830- en que la animosidad contra Schelling alcanza su paroxismo en los escritos de Schopenhauer, ese inesperado reconocimiento de Vorspuke? Podría pensarse que, después de muchos años sin manejar el escrito de Schelling, el reencuentro con éste podría haber supuesto una sorpresa para Schopenhauer, que hasta entonces, inmerso en la vorágine del proceso de gestación de su sistema, habría tendido a olvidar las «deudas» con autores que le pudieron influir en ciertos aspectos: tal sorpresa sería, pues, la que habría originado estas anotaciones. En éstas, por cierto, Schopenhauer reconoce la similitud, pero de mala gana: afirmar que se trata de «presagios» dista mucho de reconocer un influjo; ahora bien, puesto que sabemos que la obra de Schelling había sido estudiada por el joven Schopenhauer antes de desarrollar su sistema, y en concreto antes de

89 Spuk viene a ser una aparición fantasmagórica, presencia de duendes, etc.; así que un Vor-spuk sería una tal aparición, pero que se presenta como augurio, presagio o premonición de lo futuro. El célebre diccionario de Adelung confirma esta interpretación: Grammatisch-kritisches Wörterbuch der Hochdeutschen Mundart, Bd. 4, Leipzig, 1801, p. 1301. Ninguno de los dos pasajes donde Schopenhauer hace esta concesión es, contra lo que tal vez cabría esperar, el de la famosa sentencia «Wollen ist Urseyn» (Schelling, SW VII, 350), sino otros dos donde la misma idea se expresa con algo más de concreción: primero, allí donde Schelling afirma que «el Principio, en cuanto procede del fundamento y es oscuro, es la voluntad propia de la criatura, la cual [voluntad], empero, en la medida en que aún no se ha elevado (pues no la capta) a la perfecta unidad con la luz (como Principio del entendimiento), es mero afán o apetito [Sucht oder Begierde], es decir, es voluntad ciega» (Phil. Schriften, I, p. 436 = SW VII, 363); y, por segunda vez, donde se lee que «en todas partes donde hay ganas y apetito [Lust und Begierde], ya hay en sí una especie de libertad, y nadie creerá que el apetito, que constituye el fundamento de toda vida natural particular, y el impulso a mantenerse, no sólo en general, sino en esta existencia determinada, haya de añadirse primero a la criatura ya creada, sino más bien que aquél [apetito] fue él mismo lo creador» (ibid. p. 455 = SW VII, 376). En ambos casos, el comentario de Schopenhauer es telegráfico pero lapidario: «Presagio de mí» («Vorspuk von mir»), escribe: HN V 147, comentarios a pp. 436 y 455. 
determinar la voluntad como la «cosa en sí», diríase que la negativa a reconocer el influjo es producto de cierta obstinación. Una interpretación de este estilo, en la línea del «olvido interesado» (acaso inconsciente) de la influencia, parece ser la que hay a la base de la opinión de Tilliette según la cual «si Schopenhauer ha denunciado con virulencia los plagios de Schelling, tal vez es porque no tenía la conciencia tranquila» y por ello también «se defiende ásperamente de plagiar» ${ }^{90}$. Dejando de momento de lado esta hipótesis, nosotros creemos que no es la sorpresa del «reencuentro» con pasajes coincidentes con sus propias doctrinas lo que ocasiona esas dos anotaciones sino que más bien, como suele suceder con las notas manuscritas de Schopenhauer, se trata de la primera expresión, en esta ocasión apenas más que un garabato, de un pensamiento con vistas a su posterior desarrollo y publicación. El pensamiento en cuestión comienza a expresarlo propiamente en un fragmento de 1837, aproximadamente contemporáneo de aquellas anotaciones, en el que escribe: «Fichte y Schelling están en mí, pero yo en ellos no: es decir, lo poco de verdadero que hay en sus doctrinas se contiene en lo que yo he dicho» ${ }^{91}$. Este fragmento muestra que a Schopenhauer en esa fecha le comienza a interesar ponerse en claro y tomar postura acerca de su posible relación positiva (esto es, de influencia) con los postkantianos. Por otra parte, encontramos, también en la misma época, anotaciones similares a las de los Vorspuke del tratado de 1809 en otras relecturas paralelas realizadas con vistas a la redacción de las dos memorias sobre Ética: en particular, en el System der Sittenlehre de Fichte ${ }^{92}$.

Tras más de una década de «latencia» de la idea, Schopenhauer redacta por fin la expresión definitiva de su toma de postura acerca de la cuestión de la influencia de los postkantianos sobre él, publicándola en los Parerga, en un pasaje del $\S 14$ de los «Fragmentos sobre la historia de la filosofía» al que ya hemos hecho referencia arriba: comenta aquí que ya al poco de aparecer Die Welt en 1818 surgió «la querella de la prioridad» con respecto a la metafísica de la voluntad y se mencionó por ejemplo el «Wollen ist Urseyn» de Schelling; Schopenhauer reconoce que «en los filosofemas de Fichte y Schelling (...) se pueden encontrar huellas del mismo pensamiento fundamental», pero la coincidencia se debería, afirma, a que los tres habrían partido de Kant, quien ya se habría aproximado mucho a ese Grundgedanke de la voluntad como «cosa en sí»: en todo caso, en Fichte y Schelling esas ideas «se presentan sin consecuencia, contexto ni desarrollo, según lo cual han de verse como un mero presagio (Vorspuk) de mi doctrina», como «un presentimiento, una premonición, una imagen confusa como en la niebla», mientras que sólo en Schopenhauer esa idea habría alcanzado pleno desarrollo y expresión ${ }^{93}$. Resulta chocante en el pasaje el que

90 Cf. X. Tilliette, op. cit., II 432. Más abajo damos la cita completa.

91 HN IV-1, 231, Pandectae, $n^{\circ} 183$ (1837). El propio Schopenhauer remite (cf. loc. cit., nota, y comentario de Hübscher) al fragmento preparatorio del pasaje que en seguida citaremos de P I, 142, lo que confirma nuestra pequeña red de conexiones entre estos fragmentos.

$92 C f$., en HN V, 53ss (n $\left.{ }^{\circ} 192\right)$, los comentarios a Fichte, System der Sittenlehre (1798), pp. 21 (según Fichte, si el muelle de acero, Stahlfeder, pudiese autointuirse, surgiría en él la conciencia de una voluntad; Schopenhauer lo aplaude, pero añade que otras páginas del libro muestran que Fichte escribía tales cosas «sin conocimiento claro y como en sueños», «wie im Traume»); 165 (si la planta pudiera reflexionar, dice Fichte, para ella el crecimiento sería un bienestar; Schopenhauer lo aplaude con un comentario similar al anterior); y, sobre todo, $\mathrm{p}$. 243: Fichte habla de «una acción motivada por el impulso (Trieb) ciego», junto a lo cual escribe Schopenhauer: «este impulso ciego es la verdadera luz 1812». Estas notas, tardías en su mayoría, deben de corresponder a una lectura preparatoria del parágrafo de la segunda memoria de BGE sobre la ética de Fichte.

93 Cf. P I, 142-144 («Fragmente zur Geschichte der Philosophie», § 14, trad. nuestra); el pasaje principal termina 
casi deje entender, no ya que se trate de simples coincidencias, sino que él no hubiera conocido esos textos de Fichte o Schelling antes de concebir su propia filosofía: ahora bien, a la luz del Nachlass (y aun de sus primeras publicaciones) sabemos que eso no es cierto en absoluto, por más que pudiera ser discutible si fueron esos pasajes de Fichte o Schelling los que despertaron sus reflexiones sobre el asunto ${ }^{94}$. Pero, sea como sea, ¿por qué esa obstinación en negar la influencia? ¿Por qué este pasaje de los Parerga? Ni siquiera su animosidad general contra los postkantianos, radicalizada en la época del éxito de Hegel y su escuela, parece ofrecer una respuesta satisfactoria, pues muy bien se puede reconocer la influencia de un autor en unas pocas doctrinas concretas y a la vez criticar el conjunto de su filosofía, a menos que se trate, efectivamente, de obstinación. Que algo de ello hubiera es difícil de negar. En todo caso, la interpretación más plausible de la intención del texto $-\mathrm{y}$, por tanto, la de los fragmentos preparatorios sobre los «presagios»- nos es puesta en bandeja por el propio Schopenhauer, al comenzar el pasaje: «Apenas habían llamado mis escritos la atención de tan sólo unos pocos, ya se pudo oír, con respecto a mi pensamiento fundamental, la querella de la prioridad...»; y lo que sigue a esta frase no consiste en otra cosa que en una toma de posición frente a dicha «querella». Es así que en varias de las pocas recensiones de las obras de Schopenhauer anteriores a los exitosos Parerga se intentaba, en efecto, reducir las novedades de su metafísica a algunas de las etapas de las filosofías de, justo, Fichte y Schelling: el filósofo Herbart había dado la pauta en 1820 en su recensión anónima de Die Welt ${ }^{95}$. Lo mismo hizo en 1836 el único recensor de Sobre la voluntad en la naturaleza, Gustav Hartenstein (que por cierto era herbartiano) ${ }^{96}, \mathrm{y}$, en 1845 , uno de los recensores de la segunda edición de Die Welt, Carl Fortlage, aseguraba que ya Fichte había establecido la voluntad como la «cosa en sí» ${ }^{97}$. No es difícil imaginar la irritación que debía de sentir un Schopenhauer aún pendiente de ver reconocida su obra al leer este pequeño corpus de recensiones: es la amenazada originalidad del pensamiento central de la voluntad lo que le lleva a escribir este pasaje de Parerga y Paralipómena, en el que le vemos hacer poco más o menos el mismo papel que él había reprochado a Kant por la crítica a Berkeley en los Prolegómenos y por los añadidos y recortes de tendencia antiidealista de la segunda edición de la $\mathrm{KrV}^{98}$, esto es, una reacción un tanto exagerada motivada por el prurito de la originalidad.

con la cita de Donato (p. 143); el resto son añadidos de la $2^{\text {a }}$ edición que aportan poco a lo esencial.

94 De modo similar a nosotros, Martin Kurzreiter, Der Begriff des Individuums in der Philosophie Arthur Schopenhauers, Frankfurt am Main: Verlag Peter Lang, 1992, p. 68, escribe acerca del pasaje de P I, 142, que «Schopenhauer hinterläßt hier den Eindruck, als wäre ihm jene Abhandlung völlig unbekannt gewesen, was de facto weder der Fall war noch ein bloßes Zwischenspiel blieb, denn noch der späte Schopenhauer wird sich in seiner Preisschrift "Zur Freiheit des menschlichen Willens” erneut auf Schelling besinnen».

95 La recensión, firmada por «E.G.Z.» (= J.F. Herbart) apareció en Hermes oder kritisches Jahrbuch der Litteratur. Drittes Stück für das Jahr 1820. Nummer 7 der ganzen Folge, pp. 131-149. Herbart remonta el concepto schopenhaueriano de la voluntad tanto a Schelling - no en vano el recensor la denomina Urwille a pesar de que Schopenhauer no emplea ese término- como al Fichte del System der Sittenlehre, quien además habría adelantado los principales rasgos de la doctrina del cuerpo (Leib) expuesta en Die Welt.

96 La recensión de WN de Hartenstein, también anónima, se publicó en: Repertorium der gesammten deutschen Litteratur. Hrsg. von E.G. Gersdorf, Bd. X (1836), pp. 367s. Hartenstein reseñó también BGE en 1841, en la misma revista (de nuevo anónimamente), y después la 2a edic. de Die Welt (1844), en el Leipziger Repertorium der deutschen und ausländischen Literatur.

97 Para la recensión de Fortlage (publicada en la Neue Jenaische Allgemeine Litteratur-Zeitung en junio de 1845), $c f$. A. Hübscher, Denker gegen den Strom, Bonn: Bouvier, 1988, p. 232s y la nota correspondiente.

$98 C f$. KKP, 515 (adición de B, 1844). 
Los argumentos de Schopenhauer en el pasaje de los Parerga no convencieron, sin embargo, a la crítica: todavía en vida de Schopenhauer ${ }^{99}$, otros recensores e intérpretes de su filosofía, al fin descubierta en los 1850, seguían insistiendo en las comparaciones con Schelling ${ }^{100}$ y con Fichte ${ }^{101}$, como se siguió y se sigue haciendo desde su muerte hasta hoy ${ }^{102}$. Y como hacen algunos especialistas en Schopenhauer ${ }^{103}$. Pues, naturalmente, las coincidencias con los dos autores mencionados son muchas, y sabemos que Schopenhauer leyó muchos de sus textos.

La cuestión de la influencia no es, hemos dicho, la nuestra aquí; no obstante, unas palabras al respecto. Creemos que en rigor no puede asegurarse de manera absoluta que aquélla exista cuando el autor supuestamente «influido» no lo reconoce y lo único de lo que disponemos son coincidencias incidentales. Por ello resulta excesiva la afirmación de X. Tilliette según la cual las denuncias de plagio de Schopenhauer a Schelling se deberían a que el primero «tal vez no tenía la conciencia en paz», añadiendo que «por su parte él ha explotado la intuición central de Schelling, la voluntad como Urseyn y su contexto de tendencias, el hambre, la necesidad, la codicia. Pero él se defiende ásperamente de plagiar» ${ }^{104}$. Ya resulta harto cuestionable que el

99 En carta al discípulo David Asher del 12 de noviembre de 1856 (GBr, 405, nº 401), Schopenhauer menciona que el teólogo G.A. Fricke y el filósofo (teísta especulativo y en esa época seguidor del Schelling de la «filosofía positiva») Ch.H. Weisse, en sendos artículos recientes (de 1856), habían vuelto a sacar el tema, invocando el Freiheitsschrift y cuestionando la originalidad de Schopenhauer. Éste menciona también que, por contraste, el ex hegeliano J. Hillebrand había negado expresamente la similitud de la doctrina de Schopenhauer con la del Schelling de 1809 en Die deutsche Nationalliteratur im 18. und 19. Jahrhundert (2. Aufl., 1850, Bd. 3, p. 385).

100 Así, J.E. Erdmann, en «Schopenhauer und Herbart, eine Antithese», en: Zeitschrift für Philosophie und philosophische Kritik, 21, 1852, y en el Versuch einer wissenschaftliche Darstellung der Geschichte der neuern Philosophie, tomos VI y VII (1853), ubicaba el sistema de Schopenhauer cerca del Schelling de la IdentitätsPhilosophie y Hegel; C.L. Michelet, en «Arthur Schopenhauer», en: Zeitschrift für Phil. und phil. Kritik, $\mathrm{n}^{\circ}$ 27, 1855, también lo comparaba con Schelling y Hegel; $c f$. además: David Asher, «Nochmals Schelling und Schopenhauer», en: Blätter für litterarische Unterhaltung, 1856, Nr. 50 (comparación con Schelling), y R. Seydel, Schopenhauers philosophisches System dargestellt und beurtheilt, Leipzig, 1857 (también el Schelling de la identidad, y el Fichte de Die Bestimmung des Menschen).

101 Como el recién citado Seydel, Fortlage también comparaba a Schopenhauer con el Fichte de 1800 y Die Bestimmung des Menschen, en: Genetische Geschichte der Philosophie seit Kant, Leipzig, 1852, pp. 407ss.

102 Para literatura de entre 1860 y los años 1920 acerca de la influencia de Schelling en general sobre Schopenhauer, cf. Hübscher, op. cit., p. 190s y la nota 18 al cap. 9 (Hübscher menciona obras de E. von Hartmann, R. Willy, K. Schewe, E. Cassirer). Para el Freiheitsschrift en particular, tenemos ejemplos más recientes en M. Heidegger: Nietzsche I, Pfullingen: Neske, 1961, p. 44s (la afirmación de una influencia de la Phänomenologie de Hegel es, empero, insostenible a pesar de lo que Heidegger invoca como «mejor prueba» en loc. cit.) y X. Tilliette, ya citado y al que a continuación volveremos; o, más próximos a nosotros, los de F. Duque, op. cit., p. 298, nota 608, y A. Leyte y V. Rühle,op. cit., pp. 61ss.

103 Por ejemplo, cf. Y. Kamata, Der junge Schopenhauer. Genese des Grundgedankens der Welt als Wille und Vorstellung, Friburgo-Múnic: Verlag Karl Alber, 1988, pp. 163ss, para la influencia de Schelling en general, y pp. 246 y 266n para la del tratado de 1809; Hübscher, en op. cit., p. 136s, reconoce de mala gana cierto papel de Schelling y Fichte en la formación del sistema de Schopenhauer; M. Kurzreiter, op. cit., pp. 63-68, dedica un apartado a «Die Frage nach einer Beeinflussigung durch Schelling», y en pp. 64ss discute muy brevemente la influencia del Freiheitsschrift. Muy insistente en las comparaciones y la cuestión de la influencia es el libro de Robert Jan Berg: Objektiver Idealismus und Voluntarismus in der Metaphysik Schellings und Schopenhauers, Würzburg: Königshausen \& Neumann, 2003. Pero, hasta donde hemos podido comprobar, lo que estos autores que insisten en las semejanzas ignoran sistemáticamente -con lo que desde luego se ponen las cosas más fáciles- es atender a las diferencias y, en particular, a la critica de Schopenhauer a Schelling en sus distintas «etapas».

104 X. Tilliette, op. cit., II, 432: «Si Schopenhauer a denoncé avec virulence les larcins de Schelling, c'est peu être qu'il n'avait pas la conscience en paix. Il a pour sa part exploité l'intuition centrale de Schelling, la volonté comme Urseyn et son contexte de tendances, la fringale, le besoin, la convoitise. Mais il se defend âprement de plagier». 
concepto de la voluntad como Urseyn sea la «intuición central» de Schelling (¿en todas sus «etapas»?) y además Tilliette ignora aquí por completo que esa «intuición» también puede hallarse en Fichte, cuya posible influencia sobre Schopenhauer en este punto quizá puede argumentarse con más solidez, por no hablar del simplismo de comparar tesis aisladas sin prestar atención a su función dentro del sistema de cada autor. Prescindiendo de todo esto, discutir lo cual sería largo, centrémonos en la «áspera defensa» a la que Tilliette hace referencia, que ha de ser ante todo el recién comentado pasaje de los Parerga: Schopenhauer no convence a Tilliette cuando, aun reconociendo coincidencias con Fichte y Schelling, se distancia de ellos con el argumento de que tales pasajes «se presentan sin consecuencia, contexto ni desarrollo», por lo que tan sólo serían como «un mero presagio (Vorspuk)», «un presentimiento, una premonición, una imagen confusa, como en la niebla». Ahora bien, aunque para el tratado sobre la libertad no disponemos de otra cosa más que las dos escuetas menciones de Vorspuke en el ejemplar de Schopenhauer, en cambio, en las anotaciones - con toda probabilidad contemporáneas- a la Sittenlehre de Fichte, Schopenhauer no sólo escribe algún comentario en la misma línea que los recién citados de Parerga, sino que da indicaciones sobre las inconsistencias que, según él, se hallan en el texto, y que le permiten considerar aquellos «presagios» como, en efecto, frases aisladas, imágenes confusas, etc. ${ }^{105}$ Estemos de acuerdo o no con él, como mínimo esto habla a favor de la honestidad con la que escribe esa «áspera defensa» de Parerga. Contra Tilliette hay que decir, además, que la primera acusación a Schelling de «plagio» de Böhme, cuya «aspereza» tiene poco que envidiar a otras posteriores, data de 1812, antes de la formulación del «pensamiento fundamental» y por tanto antes de que Schopenhauer tuviese que «ocultar»-acaso a sí mismo, sin lograr «tener la conciencia en paz»- ningún presunto «plagio» de Schelling. Lo que nos parece un argumento lo suficientemente contundente contra la acusación de Tilliette ${ }^{106}$.

\section{Conclusiones}

Terminamos la exposición de los textos de Schopenhauer relativos a su discusión con el Freiheitsschrift así como nuestra intepretación de los mismos. Recapitulando:

$105 C f$. los fragmentos de HN V, 53 ss, citados arriba en la nota 91. En uno de ellos, afirma que Fichte escribió cosas tales «como en sueños»; compárese con la expresión «un hablar en sueños» de P I, 142.

106 Respecto a la posible motivación última de las acusaciones a Schelling de plagio (de Boehme y Kant en lo que se refiere al Freiheitsschrift) en la obra publicada, posiblemente haya que buscarla en la poco conocida «campaña» personal que emprendió Schopenhauer en los años 1830 contra los plagiarios en general y que salió a la luz de manera especialmente pregnante en un pasaje de W II, 56-58, en el que sugiere que nada menos que Kant podría haber plagiado ideas de Priestley, K. F. Wolf y Maupertuis; Laplace, por su parte, habría plagiado la cosmogonía kantiana; Goethe, en su Metamorfosis de las plantas, al mencionado K. F. Wolff; y Newton, a Hooke. Comparado con este pasaje, donde ni aun los héroes de Schopenhauer-Kant y Goethe-salen librados, las acusaciones de plagio a Schelling dan mucho menos la impresión -si es que la daban- de deberse a una manía personal, sobre todo teniendo en cuenta que están mucho mejor fundadas. Lo que parece haber dado pie al asunto, hacia 1836 o algo antes, es el hecho de que Schopenhauer mismo creyó haber sido plagiado, primero por un tal Prof. Rosas (sobre el cual se explaya en WN, 14s) y después por el médico J.D. Brandis (cf. W II, 295s, y en la $2^{\mathrm{a}}$ edic. [1854] de WN, p. 13s); en 1836 redactó además en relación con el tema los fragmentos $\mathrm{n}^{\circ} 173$ y 175 del cuaderno Pandectae ( $c f$. HN IV-1, 226-228). Todo esto explica que, a menudo, los pasajes publicados acerca del tema den la impresión de que Schopenhauer se toma la cosa en términos personales; a su vez, si tenemos a la vista el conjunto de pasajes donde el asunto de los plagios sale a colación, la perspectiva sobre la polémica con Schelling y los plagios en su tratado de 1809 se modifica sustancialmente. 
en los $\S \S 2$ y 3 hemos podido seguir la evolución de la relación de Schopenhauer con el tratado, comenzando por el cuadernillo de 1812, en el que se manifiesta un cierto desinterés por el libro; algunas críticas se esbozan ya allí pero sobre todo comienzan a desarrollarse en la época de gestación de Die Welt, culminando en el juicio sobre el «filosofar histórico» en dicha obra. Una segunda fase importante llega con la relectura del libro a mediados de los años 1830 , con vistas a comentarlo en la memoria sobre la libertad de 1838; en esta fase es en la que se presentan los más duros ataques y, sin embargo, parece ser esta misma intensificación de la relación con el tratado de Schelling la que conduce a Schopenhauer a reconocerle finalmente, en los Parerga, cierto valor filosófico. Prescindiendo de la cuestión de las imitaciones o plagios (de Böhme y Kant), las críticas doctrinales de Schopenhauer pueden agruparse en dos temas principales, a saber, la polémica ético-soteriológica y la crítica al proyecto de Schelling como retroceso a la ontoteología dogmática combatida por Kant. Aunque en la obra publicada de Schopenhauer esta segunda perspectiva es la dominante, hemos argumentado ( $§ 4)$ las razones por las que consideramos que la polémica fundamental es más bien la primera, que se mantiene vigente, aunque soterrada, como trasfondo de la segunda. Finalmente, hemos comentado (§ 5), junto a los fragmentos preparatorios, el pasaje de Parerga donde Schopenhauer reconoce, no la influencia, pero sí el carácter precursor de ciertas doctrinas de Schelling con respecto a otras suyas, lo que nos ha llevado a entrar un poco en la discusión de la influencia de Schelling sobre la filosofía de Schopenhauer.

En este artículo, pues, nos hemos servido de la tesis del trasfondo éticosoteriológico de la polémica de Schopenhauer con el Freiheitsschrift como hilo conductor para la exposición de las principales críticas de contenido a la obra. No hemos desarrollado los argumentos en los que Schopenhauer funda dichas críticas por la sencilla razón de que él mismo no lo hace, y, por otra parte, las alusiones irónicas y paródicas a las que se reducen en su mayor parte dichas críticas son por sí mismas lo bastante expresivas como para necesitar de ulteriores explicaciones. En su lugar, el intento de mostrar un debate velado, incluso totalmente soterrado, en las críticas que llegó a publicar puede abrir alguna perspectiva nueva a la hora de entender el rechazo de Schopenhauer hacia ese tratado que, en algunos aspectos, presenta tantas similitudes con su metafísica, como se ha señalado con frecuencia, y de este modo ofrecer una alternativa a algunas explicaciones psicologistas ${ }^{107}$ que se han sugerido para explicar el contraste entre aquel obstinado rechazo del tratado y negación de la influencia por una parte y esas coincidencias por otra.

107 Aludimos en particular a X. Tilliette, citado supra en el texto principal,y a M. Heidegger en loc. cit. 